\title{
An Hb-mediated circulating macrophage contributing to pulmonary vascular remodeling in sickle cell disease
}

Katherine Redinus, ${ }^{1}$ Jin Hyen Baek, ${ }^{2}$ Ayla Yalamanoglu, ${ }^{2}$ Hye Kyung H. Shin, ${ }^{2}$ Radu Moldova, ${ }^{3}$ Julie W. Harral, ${ }^{1}$ Delaney Swindle, ${ }^{1}$ David Pak, ${ }^{1}$ Scott K. Ferguson, ${ }^{1}$ Rachelle Nuss, ${ }^{4}$ Kathryn Hassell, ${ }^{4}$ Eva Nozik-Grayck, ${ }^{1}$ Andre F. Palmer, ${ }^{5}$ Mehdi A. Fini, ${ }^{1}$ Vijaya Karoor, ${ }^{1}$ Kurt R. Stenmark, ${ }^{1}$ Paul W. Buehler, ${ }^{2}$ and David C. Irwin'

${ }^{1}$ Cardiovascular and Pulmonary Research Laboratory, Department of Medicine, Anschutz Medical Campus, University of Colorado-Denver School of Medicine, Aurora, Colorado, USA. 'Division of Blood Components and Devices, Office of Blood Research and Review, The Center for Biologics Evaluation and Research, United States Food and Drug Administration, Silver Spring, Maryland, USA. ${ }^{3}$ Advanced Light Microscopy Core Facility and ${ }^{4}$ Division of Hematology and Colorado Sickle Cell Treatment and Research Center, School of Medicine, Anschutz Medical Campus, University of Colorado-Denver School of Medicine, Aurora, Colorado, USA. ${ }^{5}$ William G. Lowrie Department of Chemical and Biomolecular Engineering, The Ohio State University, Columbus, Ohio, USA.

Circulating macrophages recruited to the lung contribute to pulmonary vascular remodeling in various forms of pulmonary hypertension (PH). In this study we investigated a macrophage phenotype characterized by intracellular iron accumulation and expression of antioxidant (HO-1), vasoactive (ET-1), and proinflammatory (IL-6) mediators observed in the lung tissue of deceased sickle cell disease (SCD) patients with diagnosed $\mathrm{PH}$. To this end, we evaluated an established rat model of group $5 \mathrm{PH}$ that is simultaneously exposed to free hemoglobin ( $\mathrm{Hb}$ ) and hypobaric hypoxia (HX). Here, we tested the hypothesis that pulmonary vascular remodeling observed in human SCD with concomitant PH could be replicated and mechanistically driven in our rat model by a similar macrophage phenotype with iron accumulation and expression of a similar mixture of antioxidant (HO-1), vasoactive (ET-1), and inflammatory (IL-6) proteins. Our data suggest phenotypic similarities between pulmonary perivascular macrophages in our rat model and human SCD with $\mathrm{PH}$, indicating a potentially novel maladaptive immune response to concomitant bouts of $\mathrm{Hb}$ and $\mathrm{HX}$ exposure. Moreover, by knocking out circulating macrophages with gadolinium trichloride $\left(\mathrm{CdCl}_{3}\right)$, the response to combined $\mathrm{Hb}$ and hypobaric $\mathrm{HX}$ was significantly attenuated in rats, suggesting a critical role for macrophages in the exacerbation of SCD PH.
Authorship note: PWB and DCI contributed equally to this work.

Conflict of interest: The authors have declared that no conflict of interest exists.

Copyright: (c) 2019, American Society for Clinical Investigation.

Submitted: February 1, 2019

Accepted: June 19, 2019

Published: August 8, 2019.

Reference information: /CI Insight. 2019;4(15):e127860

https://doi.org/10.1172/jci.

insight.127860.

\section{Introduction}

Pulmonary hypertension $(\mathrm{PH})$ develops in approximately $6 \%-10 \%$ of patients with sickle cell disease (SCD) (1). The type of $\mathrm{PH}$ that manifests in SCD is distinguished more specifically as either precapillary or left heart disease-mediated, with each type affecting $3 \%$ and $6 \%$ of patients, respectively (2). $\mathrm{PH}$ that occurs in SCD as a result of either cause is associated with common features of pulmonary vascular remodeling characterized by abnormal growth and thickening of the intimal, medial, and adventitial layers of the precapillary vascular wall and eventual right ventricular (RV) failure $(1,3)$. The pathobiology of $\mathrm{PH}$ is influenced by several factors; however, unique to hemolytic disease syndromes is the constant exposure of the pulmonary vasculature to extracellular hemoglobin $(\mathrm{Hb})$ in a setting of tissue hypoxia (HX), oxidation, and proinflammatory mediators (4-6). Heme oxygenase-1 (HO-1) induction occurs during intravascular hemolysis in the process of $\mathrm{Hb} /$ heme detoxification and is an effective antioxidant cellular stress response $(7,8)$. Conversely, iron is a potential cellular prooxidant, whereas IL- 6 and ET-1 proteins are inflammatory, vasoactive, and mitogenic mediators. All 3 are extensively implicated in the progression of HX-induced PH $(9,10)$. Despite these obvious connections, our understanding of the effects of these disease-modifying factors in SCD patients with diagnosed $\mathrm{PH}$ and disease progression is poor. 
It is well recognized that cell-free $\mathrm{Hb}$ plays a significant role in the development and progression of both precapillary and left heart disease $\mathrm{PH}$ in hemolytic diseases. $\mathrm{NO}$ avidly reacts with oxyHb $\left(\mathrm{HbO}_{2}\right)$ or binds to deoxyHb $\left(\mathrm{HbFe}^{2+}\right)$, decreasing $\mathrm{NO}$ bioavailability and causing persistent vasoconstriction in the pulmonary and systemic circulation (4). Similar to other forms of $\mathrm{PH}$, pulmonary vascular inflammation also contributes to the development and progression of the $\mathrm{PH}$ process in $\operatorname{SCD}(11,12)$. Although many cell types contribute to pulmonary vascular inflammation, including endothelial, smooth muscle, and fibroblasts, emerging evidence suggests that circulating macrophages recruited to the lung may be potent contributors to the pathophysiology of $\mathrm{PH}(13,14)$. This is demonstrated in $\mathrm{HX}$-induced $\mathrm{PH}$ models in which selective depletion of circulating monocyte/macrophage cell populations prevents pulmonary adventitial remodeling $(14,15)$.

As a plastic phenotypic cellular population, the monocyte/macrophage lineages efficiently respond to environmental signals and undergo a wide spectrum of polarized activation that can be proinflammatory, antiinflammatory, or a mixture of both depending on the disease state and microenvironment (16). Similarly, macrophages can be mixtures of prooxidant and antioxidant populations that in some circumstances express mitogenic and vasoactive substances. Therefore, circulating macrophages in SCD patients with concurrent $\mathrm{PH}$ may be phenotypically altered by a combination of $\mathrm{Hb}$ and $\mathrm{HX}$. This spectrum may include a mixture of $\mathrm{Hb} /$ heme clearance macrophages that fall into the antiinflammatory spectrum alongside proinflammatory phenotypes influenced by tissue injury and HX.

Despite this intriguing possibility, there are no investigations into the influence of the macrophage on $\mathrm{PH}$ associated with an increase in cell-free $\mathrm{Hb}$ and hypoxic conditions. Therefore, the purpose of this investigation was to evaluate the phenotypic similarities between pulmonary perivascular macrophages in a preclinical model and SCD patients with $\mathrm{PH}$ to assess the maladaptive immune response to concomitant bouts of $\mathrm{Hb}$ and $\mathrm{HX}$ exposure. We used lung tissue obtained from human SCD patients at autopsy with a clinical diagnosis of $\mathrm{PH}$ and right heart failure and applied several immunohistochemical techniques to visualize lung remodeling and accumulation of adventitial macrophages.

In addition, using rats chronically exposed to $\mathrm{Hb}$ and $\mathrm{HX}$, a model of group $5 \mathrm{PH}$ characterized in our laboratory, $(17,18)$, we tested the hypothesis that the vascular remodeling observed in humans could be replicated in this model and may be mechanistically driven by this macrophage phenotype containing iron and expressing a similar mixture of antioxidant, vasoactive, and inflammatory phenotype characteristics, consistent with those observed in human SCD PH. Results from this investigation shed light on the critical phenotypic similarities between macrophages obtained from a preclinical model of $\mathrm{PH}$ and those from the SCD patient population, thus indicating a potentially novel maladaptive immune response to concomitant bouts of $\mathrm{Hb}$ and $\mathrm{HX}$ exposure.

\section{Results}

Severe pulmonary vascular medial and intimal remodeling in human SCD patients with $\mathrm{PH}$ To visualize pulmonary vascular remodeling in a group $5 \mathrm{PH}$-specific disease, peripheral lung tissue sections obtained from 3 deceased SCD patients with clinically diagnosed $\mathrm{PH}$ and right heart failure were stained with H\&E. Microscopic examination revealed extensive pulmonary vascular remodeling characterized by intimal thickening, recanalization channels, endothelial hyperplasia with precapillary arteriole plexiform lesions, and pulmonary artery (PA) medial vascular wall thickening (Figure 1A). In contrast and for comparison, pulmonary vascular remodeling was not evident in human lung tissue from a person without SCD or PH (Figure 1B).

\section{Iron accumulation in lung macrophages}

Specific to humans but also observed in rats, $\mathrm{Hb}$ bound to haptoglobin is cleared by $\mathrm{CD} 163^{+}$monocytes/ macrophages (19), resulting in $\mathrm{Hb}$ metabolism by HO-1 and accumulation of intracellular ferritin-bound/ free iron. Thus, staining lung tissue sections for nonheme iron deposition is a useful indicator of the cellular distribution of $\mathrm{Hb}$. Perls-DAB iron staining of lung tissue from the deceased SCD patients revealed an abundance of iron-laden cells in the adventitial and alveolar regions, suggesting that both regions recruited circulating perivascular and resident $\mathrm{CD} 163^{+} / \mathrm{HO}-1^{+}$alveolar macrophages that compartmentalize/metabolize free $\mathrm{Hb}$ (Figure 1C). As expected, we did not observe nonheme iron accumulation in any regions of the tissue sections obtained from the control lung (Figure 1B). 
A

Sickle cell disease lung tissue
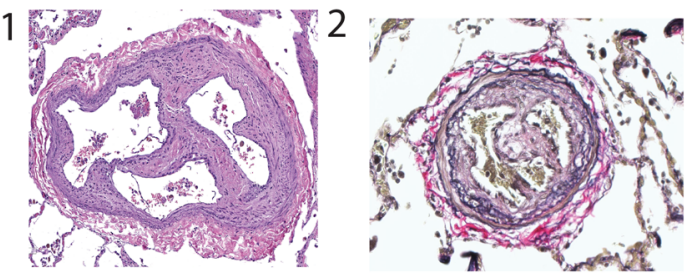

3

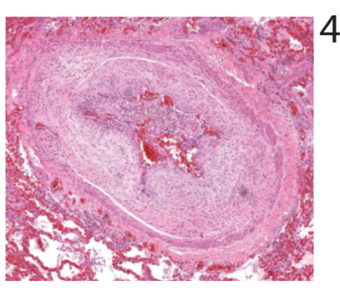

PA medial layer

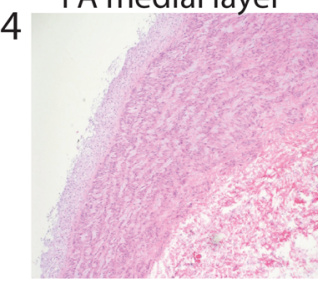

B

Human control lung tissue

PA medial layer

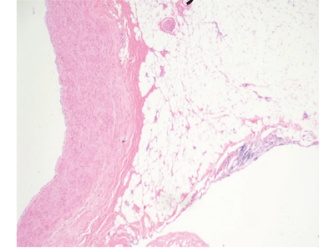

C iron deposition
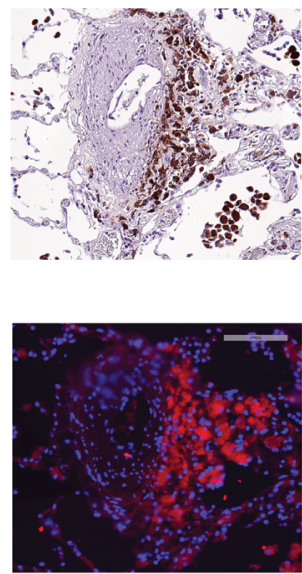

CD $163^{+}$cells
$\mathrm{CD} 163^{+} / \mathrm{HO}-1^{+}$

cells (merge)
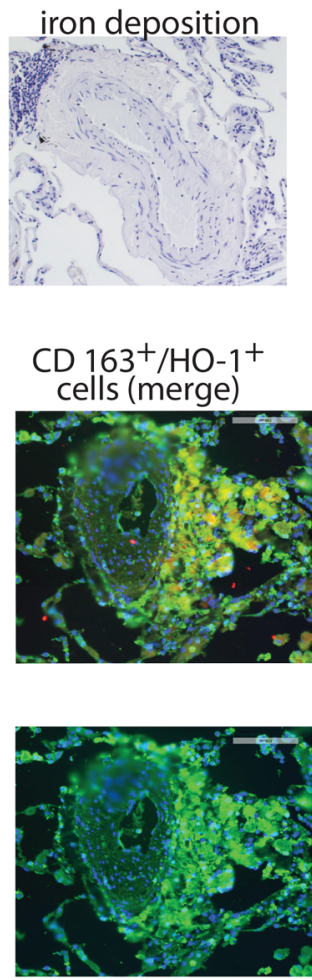

$\mathrm{HO}-1^{+}$cells
D iron deposition
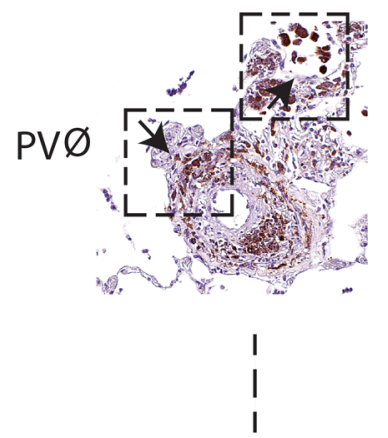

E
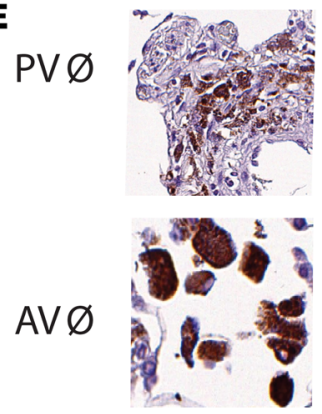

HO- ${ }^{+} / \mathrm{ET}^{-1}{ }^{+}$cells (merge)

$A V \varnothing$

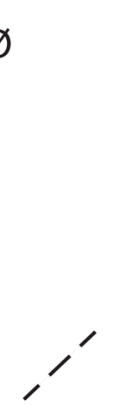

$\mathrm{HO}-1$
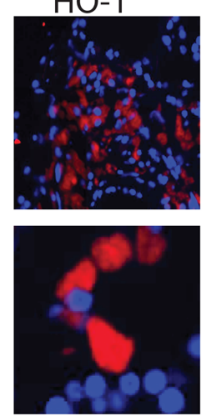
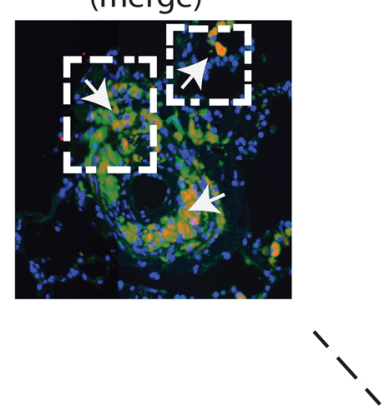

ET-1
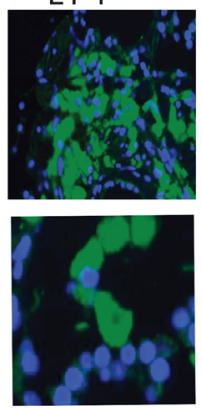
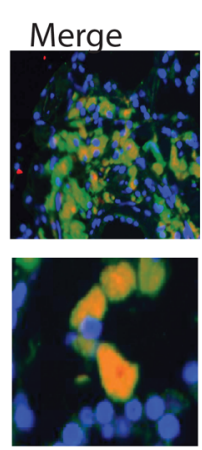

$\mathrm{HO}-1^{+} / \mathrm{IL}-6^{+}$cells (merge)
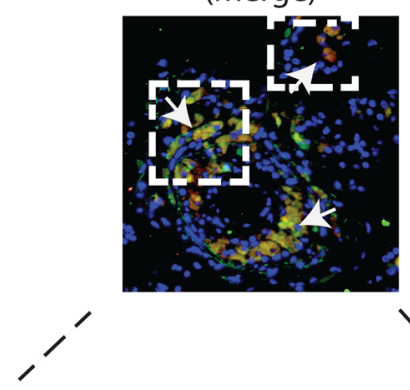

HO-1
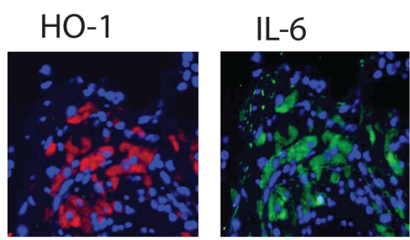

Merge
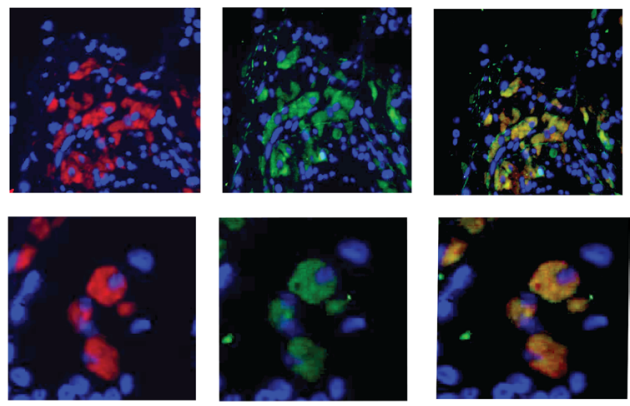
Figure 1. Microscopic examination of peripheral lung tissue slices of deceased sickle cell disease patients with confirmed pulmonary hypertension. (A) Verhoeff Van Gieson- (top row) and H\&E-stained (bottom row) lung tissue sections (original magnification, $\times 10$ ) showing extensive constrictive lesions in the pulmonary vasculature remodeling characterized by (top row) intimal thickening and recanalization channels (obtained from 2 deceased patients), (bottom left) plexiform lesion formation, and (bottom right) medial thickening in the pulmonary artery. (B) Lung tissue from person without sickle cell disease or confirmed pulmonary hypertension (PH). Normal medial layer in the pulmonary arterial wall (original magnification, $\times 10$ ); iron staining was negative in human control lung tissue for any cells, including vascular, perivascular, or alveolar regions (original magnification, $\times 20$ ). (C) In contrast to human control tissue, many perivascular and alveolar cells stain positive for iron in tissue from sickle cell disease (SCD) with confirmed PH (original magnification, $\times 20$ ) that also stain positive for CD163 and HO-1, demonstrating a macrophage phenotype. (D) In SCD with PH, the iron-laden cells staining positive for HO-1 also stain positive for ET-1 and IL-6, suggesting a unique prooxidant $\left(\mathrm{Fe}^{+}\right)$, antioxidant ( $\left.\mathrm{HO}-1\right)$, vasoactive (ET-1), and inflammatory macrophage phenotype. (E) Zoomed-in perivascular and alveolar regions containing this macrophage phenotype (original magnification, $\times 20$ ). PV, perivascular; AV, alveolar.

\section{Expression of a potentially novel macrophage phenotype found in lung autopsy tissue of} SCD patients with $\mathrm{PH}$

$\mathrm{HO}-1$ is a critical enzyme in the process of $\mathrm{Hb}$ detoxification, and its expression imparts cellular protection against oxidative stress $(7,8)$ while acting as a useful marker for $\mathrm{Hb} /$ heme exposure. Following $\mathrm{Hb}$ metabolism, iron accumulates intracellularly, presenting a prooxidative risk upon ferritin saturation. In addition, IL-6 and ET-1 proteins are inflammatory and/or mitogenic mediators, respectively, implicated in the development and progression of HX-induced PH $(9,10)$. Relevant to the current study, we immunohistochemically evaluated serial lung tissue sections for coexpression of HO-1 with either ET-1 or IL-6 to gain an understanding of the $\mathrm{Hb} / \mathrm{HX}$-induced imbalance surrounding iron (a potential prooxidant) accumulation in cells and the antioxidant, vasoactive, mitogenic, and inflammatory responses generated within the pulmonary microenvironment macrophages of our SCD autopsy tissues. Microscopic evaluation revealed the expression of these proteins in the pulmonary vascular tissue of distal arteries (Figure 1D). On closer examination, we observed HO- $1^{+}$cells colocalized with either ET- $1^{+}$or IL- $6^{+}$cells in the perivascular and alveolar regions (Figure 1, D and E). Taken together, these data suggest that in SCD, concomitant with $\mathrm{PH}$, there is an imbalance of antioxidant $\left(\mathrm{HO}-1^{+}\right.$) versus prooxidant (iron ${ }^{+}$), vasoconstrictive/mitogenic $\left(\mathrm{ET}-1^{+}\right)$, and inflammatory/mitogenic (IL- $\left.6^{+}\right)$macrophage phenotype that appears to favor dramatic vascular remodeling.

\section{Macrophage depletion attenuates pulmonary vascular remodeling in a $\mathrm{Hb}+\mathrm{HX}$ rat model of $\mathrm{PH}$}

To better understand the sequence of hemolysis and HX leading to potentially unique pulmonary macrophage subpopulations as contributors toward vascular remodeling, rats were maintained for 35 days on constant $\mathrm{Hb}$ infusion and concomitantly exposed to hypobaric $\mathrm{HX}$. Under these conditions, rats develop pulmonary vascular changes that replicate some of the characteristics of group $5 \mathrm{PH}$ (lung iron accumulation, medial hypertrophy, and an abundance of perivascular macrophages) $(17,18)$. Based on this previous knowledge and our emerging data from SCD autopsy tissue (20), we sought to test the hypothesis that $\mathrm{Hb}$ and HX lead to a unique $\mathrm{CD}_{163^{+}}$macrophage phenotype containing iron and expressing HO-1, ET-1, and IL-6 that are recruited to the lung from the circulating monocyte/macrophage pool and could be a mechanistic driver in some patients with SCD PH. Studies were designed to systematically deplete circulating macrophages with gadolinium trichloride $\left(\mathrm{GdCl}_{3}\right)$ in our $\mathrm{Hb}+\mathrm{HX}$ rat $\mathrm{PH}$ model (Figure 2A). Groups consisted of normoxic control (NX), $\mathrm{Hb}+\mathrm{HX}$, and $\mathrm{Hb}+\mathrm{HX}+\mathrm{GdCl}_{3}$; serial echocardiography as well as endpoint hemodynamics, Fulton index (RV/LV+S), and lung morphology/histology at 2 time points (day 18 and day 35) assessed the effect of macrophage depletion on the progression of $\mathrm{PH}$. Echocardiography analysis revealed that, compared with the $\mathrm{Hb}+\mathrm{HX}+\mathrm{GdCl}_{3}$ and control $(\mathrm{NX})$ rats, $\mathrm{Hb}+\mathrm{HX}$ rats demonstrate slower PA acceleration times (PAATs) and greater measurements of RV wall thickness over the study time course (Figure 2, B-D), suggesting active PH.

Invasive hemodynamic measurements obtained at study endpoints show a $20 \%$ reduction in mean PA pressure (PAP) at day 35 in $\mathrm{Hb}+\mathrm{HX}+\mathrm{GdCl}_{3}$ rats compared with $\mathrm{Hb}+\mathrm{HX}$-exposed rats (Figure 2E). The Fulton index calculation (RV/LV+S) revealed $25 \%$ less RV hypertrophy at the 18- and 35-day endpoints in the $\mathrm{Hb}+\mathrm{HX}+\mathrm{GdCl}_{3}$ versus the $\mathrm{Hb}+\mathrm{HX}$ group of rats (Figure $2 \mathrm{~F}$ ). Morphological assessment for determination of medial hypertrophy shows circulating macrophage depletion with $\mathrm{GdCl}_{3}$-attenuated medial remodeling in the distal pulmonary arteries at days 18 and 35 (Figure 2, G and $\mathrm{H}$ ), congruent with both hemodynamic and Fulton index values. Taken together, these data support the hypothesis that monocytes/ macrophages are a significant contributor to the progression and severity of $\mathrm{PH}$ in $\mathrm{Hb}+\mathrm{HX}$-exposed rats. 
A (1) NX

(2) $\mathrm{Hb}+\mathrm{HX}$

(3) $\mathrm{Hb}+\mathrm{HX}+\mathrm{GdCl}_{3}$ *
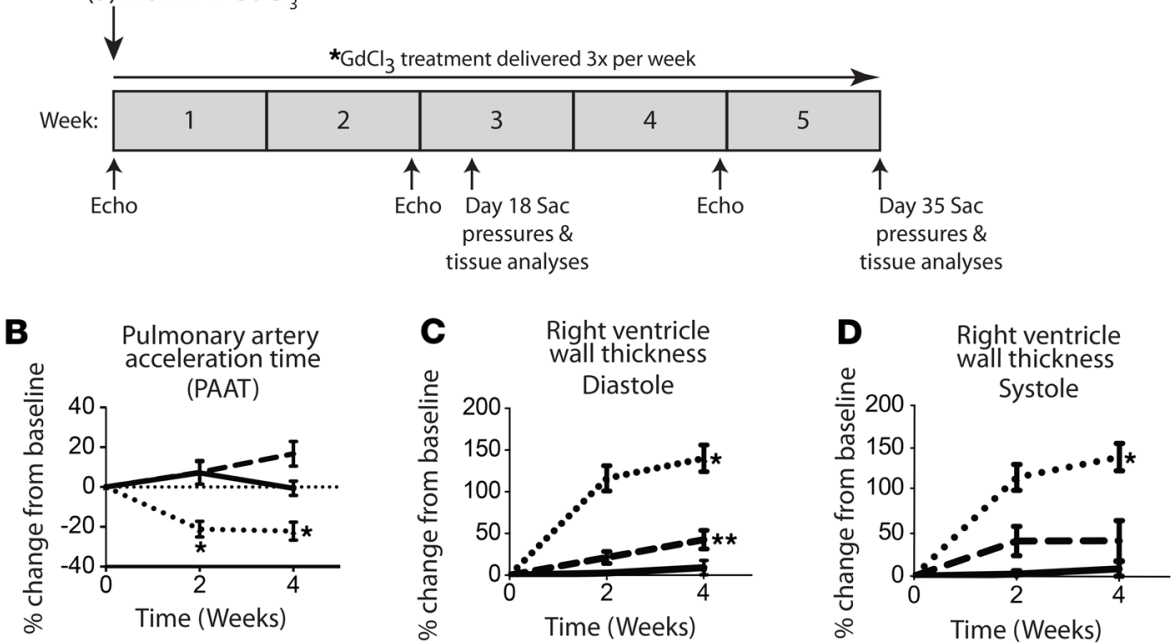

$\rightarrow$ control (NX) $\quad \cdots \Delta \cdot \cdot \mathrm{Hb}+\mathrm{HX} \leadsto \mathrm{Hb}^{\mathrm{H}}+\mathrm{HX}+\mathrm{GdCl}_{3}$

$\mathbf{E}$

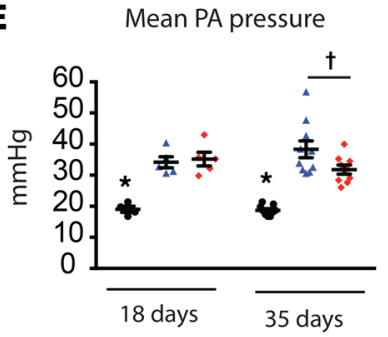

G

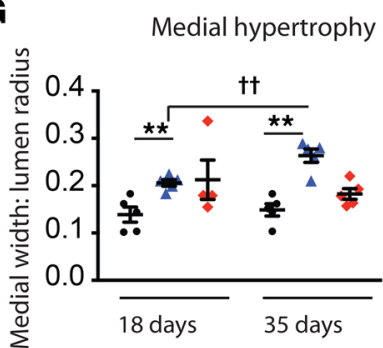

\section{$\mathbf{F}$}

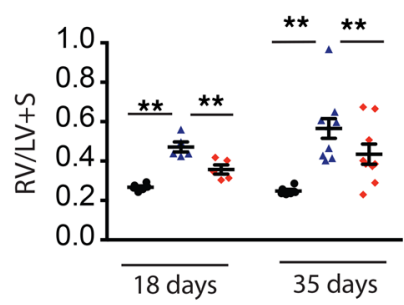

H

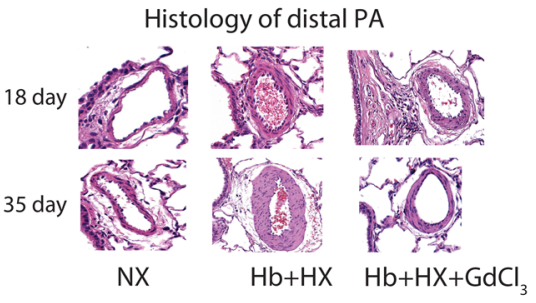

Figure 2. Circulating macrophage depletion in rats chronically infused with $\mathrm{Hb}$ and exposed to hypoxia. (A). Treatment cohorts and experimental design. Echocardiography analysis of (B) pulmonary artery acceleration time and ( $\mathbf{C}$ and $\mathbf{D})$ right ventricular wall thickness in diastole and systole. Endpoint hemodynamic measurements of $(\mathbf{E})$ mean pulmonary artery pressure, (F) Fulton index of right ventricular hypertrophy, (C) morphological analysis of pulmonary arterial medial thickness. (H) Representative microphotographs of $\mathrm{H} \& \mathrm{E}$-stained lungs from each group. Data represent mean \pm SEM; $(\mathbf{B}-\mathbf{F})$ $\mathrm{Nx}(n=4), \mathrm{Hb}+\mathrm{HX}(n=7), \mathrm{Hb}+\mathrm{HX}+\mathrm{CdCl}_{3}(n$ = 7) per group/time point; panel $\mathrm{G} \mathrm{Nx}(n=$ 4), $\mathrm{Hb}+\mathrm{HX}(n=5), \mathrm{Hb}+\mathrm{HX}+\mathrm{CdCl}_{3}(n=5)$ per group/time point. (H) Representative sample of animals in B-F. Echocardiography statistical analysis was completed with univariate repeated measures. ${ }^{*} P<0.01 \mathrm{Hb}+\mathrm{HX}$ versus $\mathrm{NX}$ and $\mathrm{Hb}+\mathrm{HX}+\mathrm{CdCl}_{3} .{ }^{* *} P<0.04, \uparrow P<$ 0.05 , 1-way ANOVA of 35-day cohorts. $\dagger+P$ $=0.0065 t$ test 18 -day $\mathrm{Hb}+\mathrm{HX}$ versus 35 -day $\mathrm{Hb}+\mathrm{HX}$.

\section{Macrophage depletion in rat model attenuates the} accumulation of nonheme iron in the lungs

In $\mathrm{Hb}+\mathrm{HX}$-exposed rats, we have previously demonstrated that lung iron deposition occurs after 35 days of chronic $\mathrm{Hb}$ exposure with concomitant $\mathrm{HX}$ (17, 18). To determine whether lung iron deposition is associated with circulating macrophages, we visualized nonheme iron deposition in lung sections from all groups. Tissue Perls-DAB staining did not reveal lung iron accumulation in any of the animals euthanized on day 18 (Supplemental Figure 1A; supplemental material available online with this article; https://doi.org/10.1172/jci.insight.127860DS1). This observation suggests that with a $\mathrm{Hb}$ exposure of $1.5 \mathrm{mg} / \mathrm{h}(35 \mathrm{mg} / \mathrm{d})$ producing $\mathrm{Hb}$ at $15 \mu \mathrm{M}$ concentration that is consistent with steady-state $\mathrm{SCD}, \mathrm{Hb}$ clearance systems in our rat model are not immediately overwhelmed and sufficiently keep pace to avoid lung iron accumulation.

In rats euthanized on day 35, an abundance of lung iron dispersed throughout perivascular macrophages was observed surrounding most small- to medium-sized arteries and to a lesser extent in adjacent alveolar macrophages of $\mathrm{Hb}+\mathrm{HX}$-exposed rats (Figure 3A, black arrowheads). In contrast, the absence of circulating macrophages in $\mathrm{Hb}+\mathrm{HX}$-exposed rats showed that iron accumulation was almost nonevident (Figure 3A). Finally, the location of lung iron deposition in rats appears strikingly similar to that observed in human lung tissue slices from SCD patients with PH at autopsy (shown in Figure 1, C-E).

A lung iron ${ }^{+}, \mathrm{HO}-1^{+}, \mathrm{ET}-1^{+}$, and $\mathrm{IL}-6^{+}$macrophage phenotype is associated with pulmonary vascular remodeling in the rat model

The attenuation of lung iron deposition, pulmonary vascular remodeling, and improved hemodynamics in rats depleted of circulating macrophages for 35 days supports our hypothesis that these macrophages are mechanistically linked to $\mathrm{Hb}+\mathrm{HX}$-induced $\mathrm{PH}$ and subsequently pulmonary vascular disease. Combining 
this knowledge with our observations of macrophages expressing HO-1, ET-1, and IL-6 in human SCD lung tissue, we next sought to determine whether a similar macrophage phenotype could be contributing toward the progression of $\mathrm{PH}$ in our $\mathrm{Hb}+\mathrm{HX}$ rat model. We evaluated stained rat lung tissue sections and quantified CD163, HO-1, ET-1, and IL-6 protein expression from whole lung tissue lysates obtained from rats euthanized at both the 18- and 35-day endpoints.

18 day. As evident by cells staining positive for CD163, microscopic evaluation of tissue lung sections demonstrated a modest degree of macrophage accumulation within the perivascular and, to a lesser extent, alveolar regions in the $\mathrm{Hb}+\mathrm{HX}$-exposed rats. Cells staining positive for $\mathrm{CD} 163$ were absent in the $\mathrm{Hb}+\mathrm{HX}-$ $+\mathrm{GdCl}_{3}$ cohort (Supplemental Figure 1, B-D), suggesting that circulating macrophages are being recruited to the lung before iron accumulation.

Interestingly, $\mathrm{CD} 163^{+}$cells in $\mathrm{Hb}+\mathrm{HX}$ rats stained positive for ET-1 expression (Supplemental Figure 1D), but only modest HO-1 or IL-6 expression was observed (Supplemental Figure 1, B and C). We also noted the expression of HO-1, IL-6, and ET-1 in the pulmonary vascular wall of both the macrophage-depleted $\left(\mathrm{Hb}+\mathrm{HX}+\mathrm{GdCl}_{3}\right)$ and $\mathrm{Hb}+\mathrm{HX}$ rats, but not the NX control animals (Supplemental Figure 2, A-F). These observations suggest that at day 18, despite a lack of significant lung iron accumulation, there was a sufficient concentration of cell-free $\mathrm{Hb}$ to alter HO-1, IL-6, and ET-1 expression in pulmonary vascular cells. Plasma $\mathrm{Hb}$ concentrations were previously reported for this model to range from 5 to $15 \mu \mathrm{M}$ total plasma heme at steady state $(17,18)$.

Western blot analysis from whole lung tissue showed elevated expression of HO-1 (2- to 3-fold) and IL-6 (2- to 3-fold) in both $\mathrm{Hb}+\mathrm{HX}+\mathrm{GdCl}_{3}$ and $\mathrm{Hb}+\mathrm{HX}$ cohorts compared with $\mathrm{NX}$ animals (Supplemental Figure 2, D and E). However, ET-1 protein expression was elevated only in $\mathrm{Hb}+\mathrm{HX}$ rats, suggesting a relevant link between macrophages and lung ET-1 expression. Western blot analysis of these proteins in HX versus NX control rats revealed no differences (Supplemental Figure 3A), suggesting that changes in HO-1, IL-6, and ET-1 expression are $\mathrm{Hb}+\mathrm{HX}$-mediated responses.

35 day. Microscopic examination of lung tissue in the $\mathrm{Hb}+\mathrm{HX}$ animals revealed an abundance of macrophages in the perivascular and, to a lesser extent, alveolar regions. Unlike in the day 18 tissue sections, we observed an increased population of perivascular/adventitial and alveolar iron-laden macrophages in $\mathrm{Hb}+\mathrm{HX}$ compared with $\mathrm{Hb}+\mathrm{Hx}+\mathrm{GdCl}_{3}$ animals (Figure 3A). Expression of HO-1, ET-1, and IL-6 in $\mathrm{CD}_{163}{ }^{+}$macrophages in the $\mathrm{Hb}+\mathrm{HX}$ animals (Figure 3, B-D) that were not evident in the $\mathrm{Hb}+\mathrm{HX}+\mathrm{G}-$ $\mathrm{dCl}_{3}$ animals further suggests a link to macrophages originating in the circulation. Costaining lung tissue sections from $\mathrm{Hb}+\mathrm{HX}$ animals for $\mathrm{HO}-1 / \mathrm{IL}-6$ and $\mathrm{HO}-1 / \mathrm{ET}-1$ confirmed macrophage $\mathrm{HO}-1$ expression occurred concurrently with ET-1 and IL-6 expression (Figure 3E). This pattern of expression was absent in $\mathrm{Hb}+\mathrm{HX}+\mathrm{Cl}_{3}$ animals (Figure $3 \mathrm{~F}$ ).

Expression of HO-1, IL-6, and ET-1 in tissue sections costained with smooth muscle actin (SMA) was increased in the pulmonary vascular endothelium, media, and perivascular space of $\mathrm{Hb}$ rats compared with macrophage-depleted $\mathrm{Hb}+\mathrm{HX}+\mathrm{GdCl}_{3}$ and $\mathrm{NX}$ control rats (Figure 4, A-C). Western blot analysis from whole lung tissue showed greater expression of HO-1, ET-1, and IL-6 in the Hb+HX rats compared with macrophage-depleted $\mathrm{Hb}+\mathrm{HX}+\mathrm{GCl}_{3}$ of $\mathrm{NX}$ cohorts (Figure 4, D-F), demonstrating that circulating macrophages are primarily responsible for high expression levels of these proteins. Lung protein analysis in HX versus NX control rats showed no difference in either HO-1 or ET-1 expression, demonstrating an $\mathrm{Hb}+\mathrm{HX}$-mediated response. In contrast, we noted that IL-6 expression is significantly greater in HX versus NX control cohort (Supplemental Figure 3B), suggesting that HX is a critical mechanistic driver of IL-6 expression. Taken together with the hemodynamic results and morphological assessment (Figure 2), these data strongly support the hypothesis that macrophages are expressing a potentially unique phenotype characterized by iron accumulation antioxidant, vasoconstrictive, and inflammatory protein expression, and this macrophage phenotype is a mechanistic driver of $\mathrm{Hb}+\mathrm{HX}$-mediated $\mathrm{PH}$.

\section{Characterization of iron accumulation within SCD PH-associated macrophages and the effect on downstream targets}

Up to this point, our data from human SCD and rat $\mathrm{Hb}+\mathrm{HX}$ exposure suggest a clear distinction in the pathophysiology of hemolysis-associated $\mathrm{PH}$ compared with nonhemolytic $\mathrm{PH}$ groupings. Our data diverge from current knowledge of iron's role in pulmonary arterial hypertension (PAH) associated with group 1 and $\mathrm{PH}$ associated with groups $2-4$, in which disease progression may be facilitated by iron deficiencies $(21,22)$. To better understand how iron in its various forms (e.g., $\mathrm{Fe}^{2+}, \mathrm{Fe}^{3+}, \mathrm{Hb}$, and iron sulfur 
A NX
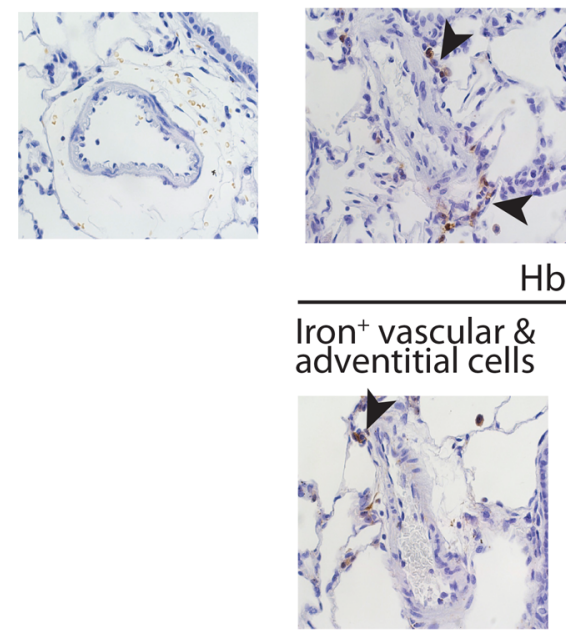

$\mathrm{Hb}+\mathrm{HX}+\mathrm{GdCl}_{3}$

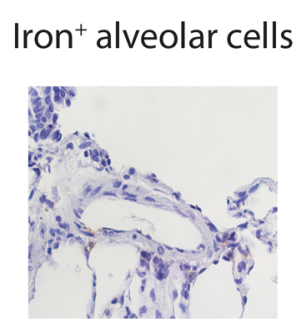

C $\quad \mathrm{IL}-6^{+} / \mathrm{CD} 163^{+}$periavscular macrophages
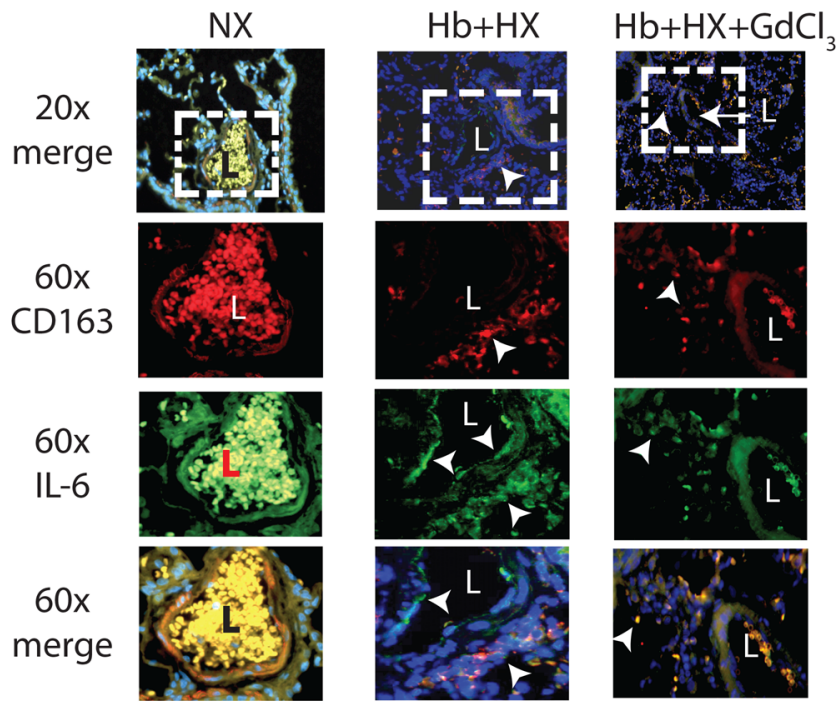

E

$\mathrm{Hb}+\mathrm{HX}$

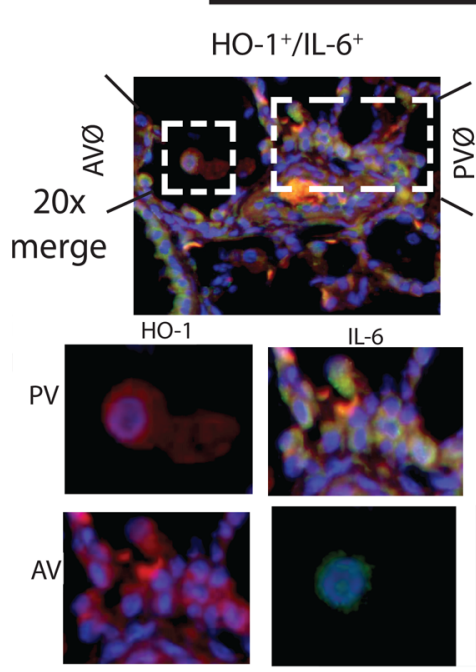

$\mathrm{HO}-1^{+} / \mathrm{ET}-1^{+}$
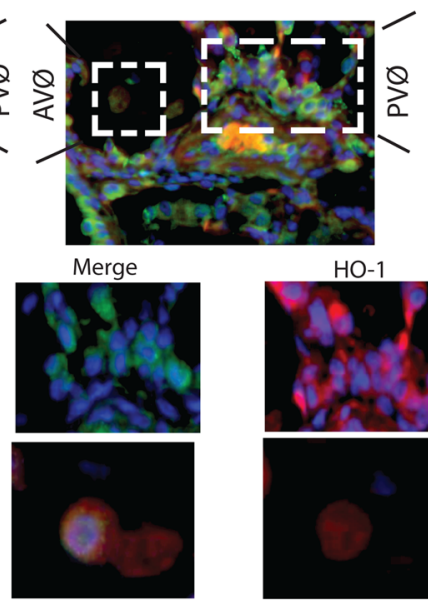

B

$\mathrm{HO}-1^{+} / \mathrm{CD} 163^{+}$perivascular macrophages

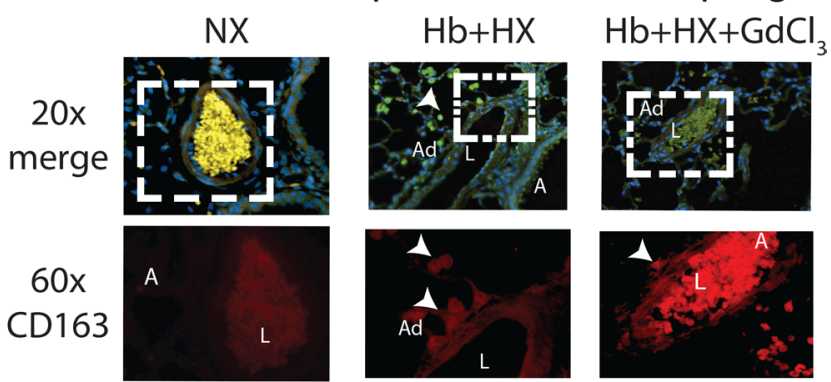

$60 x$

$\mathrm{HO}-1$

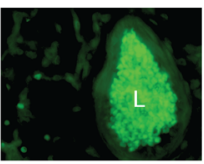

$60 x$

merge
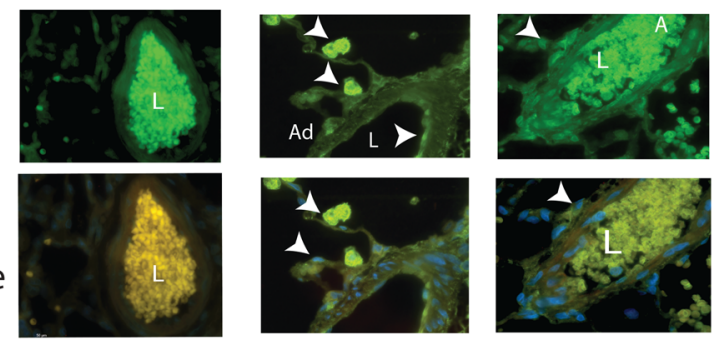

D

$\mathrm{ET}-1^{+} / \mathrm{CD} 163^{+}$

perivascular macrophages
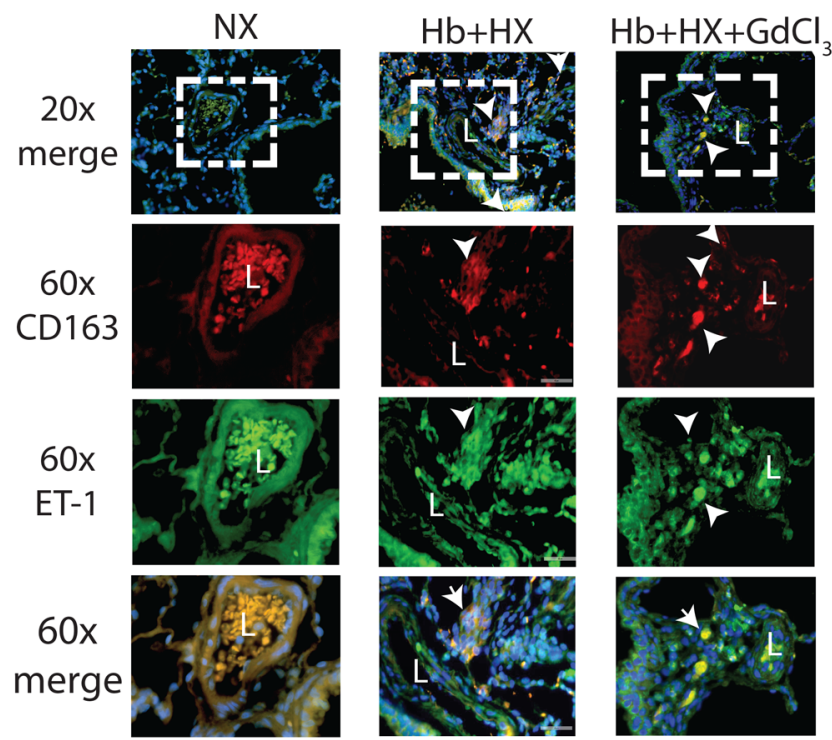

$\mathbf{F}$
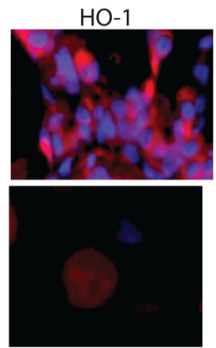

$\mathrm{HO}-1^{+} / \mathrm{ET}-1^{+}$
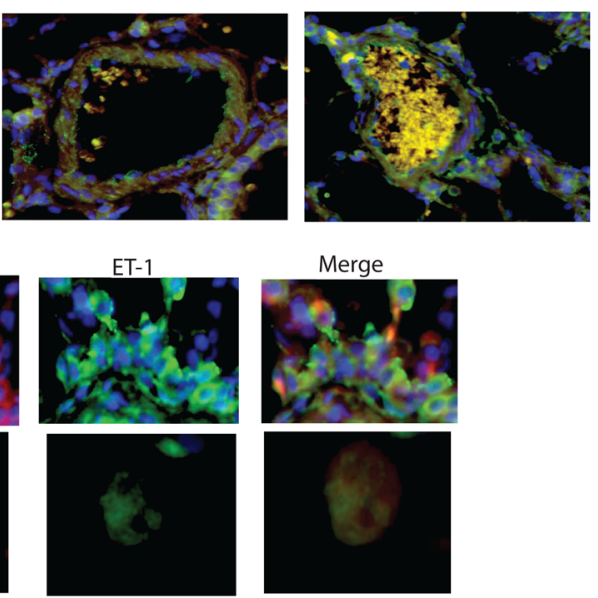
Figure 3. Microscopic examination of pulmonary perivascular and alveolar macrophages in rats after 35-day exposure to hemoglobin infusion and hypobaric hypoxia. Representative microphotographs. (A) Nonheme iron accumulation (original magnification, $\times 20$ ). Black arrowheads point to iron-laden cells. (B) Pulmonary perivascular and alveolar cells coexpressing CD163 (red) and HO-1 (green). (C) Perivascular and alveolar cells coexpressing CD163 (red) and IL-6 (green). (D) Perivascular and alveolar cells coexpressing CD163 (red) and ET-1 (green). (E) Perivascular and alveolar cells in rats exposed to Hb+hypoxia and coexpressing H0-1 (red) and either IL-6 or ET-1 (green). (F) Perivascular and alveolar cells coexpressing CD163 (red) and ET-1 (green). Representative samples from NX $(n=4), \mathrm{Hb}+\mathrm{HX}(n=7), \mathrm{Hb}+\mathrm{HX}+\mathrm{CdCl}_{3}(n=7)$; white arrowheads pointing to positive stained cells. PV, perivascular; $\mathrm{AV}$, alveolar; $\mathrm{L}$, vessel lumen; $A D$, adventitia.

clusters) localizes within macrophages from human SCD PH and rats following $\mathrm{Hb}+\mathrm{HX}$ exposure, we systematically identified cellular sources. In addition, we identified iron accumulation sites, localization with oxidative stress markers, and proximity to vascular sites of remodeling and fibrosis. In human SCD PH, adventitial macrophages demonstrated high $\mathrm{Fe}^{3+}$ (Figure 5A). Further examination using Turnbull staining revealed extensive $\mathrm{Fe}^{2+}$ in the same regions (Figure 5B) and high immunoreactivity for intact $\mathrm{Hb}$ within the macrophage (Figure 5C). Intense immunoreactivity for ferritin- $\mathrm{H}$ (Figure 5D) suggested that most $\mathrm{Fe}^{3+}$ was likely bound in an unreactive form, leaving $\mathrm{Hb}$ and $\mathrm{Fe}^{2+}$ as the primary prooxidant iron species with $\mathrm{SCD}$ $\mathrm{PH}$ lung macrophages. We further explored the localization of iron (as iron-sulfur, Fe-S) in mitochondrial ferredoxin proteins because Fe-S deficiencies have been implicated in $\mathrm{PH}(23,24)$. Ferredoxin reductase is shown colocalizing with mitochondria and iron, suggesting that intact Fe-S clusters in SCD PH (Figure $5 \mathrm{E}$ ). To understand the downstream effects of iron overload, we specifically evaluated markers of oxidation that colocalized with $\mathrm{Fe}^{2+}$ and $\mathrm{Hb}$. Accumulation of the oxidative markers 4-HNE and Ox-LDL was seen in macrophages (Figure 5F). Oxidative stress in macrophages localized with vascular regions of fibrosis (Figure 5G) and remodeling (plexiform lesions) (Figure 5G, inset). Except for $\mathrm{Fe}^{2+}$ accumulation in the macrophages of rats exposed to $\mathrm{Hb}+\mathrm{HX}$, all other iron exposure parameters could be observed (Figure 6, A-D), as visualized in human SCD PH. This extended to Fe-S cluster localization (Figure 6E) as well as 4-HNE immunoreactivity (Figure 6F) and vascular tissue fibrosis (Figure 6G).

\section{Discussion}

In the present study, we report on what we believe to be a novel monocyte/macrophage phenotype of circulating origin that accumulates in the perivascular and alveolar regions of the lungs of SCD patients with concomitant $\mathrm{PH}$. Specific to this phenotype is extensive iron accumulation resulting from $\mathrm{Hb}$ uptake and, subsequently, macrophage HO-1, ET-1, and IL-6 expression. Based on this finding, we tested the hypothesis that although $\mathrm{Hb}$ damages pulmonary vascular cells, the circulating monocytes/macrophages recruited to the perivascular regions of the lungs of SCD patients ( $n=3$ autopsy patient tissue sets) appear to be unique to this process of vascular remodeling and RV hypertrophy in $\mathrm{PH}$. To our knowledge, this is the first report that identifies this phenotypic monocyte/macrophage composition in SCD patients with malignant PH and RV failure. This suggests that $\mathrm{Hb}$ in the presence of bouts of $\mathrm{HX}$ leads to an imbalance of prooxidant/antioxidant/ inflammatory/vasoactive mediators that promote vascular remodeling and the progression of $\mathrm{PH}$ (Figure 7).

This phenotype should be considered independent of antiinflammatory/antioxidant macrophages responding to heme (Mhem) phenotypes observed in other situations of localized hemolysis, such as atherosclerotic intraplaque hemorrhage (25-27). In addition, SCD patients that develop PH experience a continuum of tissue HX, anemia, red blood cell lysis (intra- and extravascular), and the downstream effects of $\mathrm{Hb}$ and its metabolic byproducts. $\mathrm{Hb}$ is cleared by tissue-resident monocytes/macrophages and therefore exposure to prooxidant toxins ( $\mathrm{Hb}$, heme, iron) accumulate within these cellular compartments. This has been shown by our group $(17,18)$ and by Rafikova et al. $(28)$ in rodent models designed to characterize the effect of $\mathrm{Hb}$, heme, and iron exposure on $\mathrm{PH}$ disease progression. This should be considered in isolation of the current understanding applied to the role of iron in group $1 \mathrm{PAH}$ in which iron deficiency is associated with worsening PAH $(21,22)$ or when genetic/epigenetic factors and HX are associated with iron-sulfur deficiencies that may contribute toward enhanced $\mathrm{PH}$ across groups (1-4). Therefore, $\mathrm{PH}$ occurring with SCD should be viewed as a potentially unique sequela driven by cellular and tissue overexposure to $\mathrm{Hb}$ as well as byproducts of $\mathrm{Hb}$ metabolism that participate in oxidative reactions and impart intracellular oxidation and injury to vascular tissue within proximity.

Using our established rat model of $\mathrm{Hb}+\mathrm{HX}$-induced $\mathrm{PH}$, we observed a nearly identical pulmonary macrophage phenotype population within the same perivascular and alveolar locations observed in SCD patients with malignant $\mathrm{PH}$ and RV failure. Depletion of only the circulating monocytes/macrophages 
A
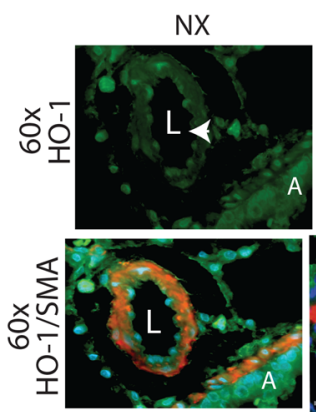

B
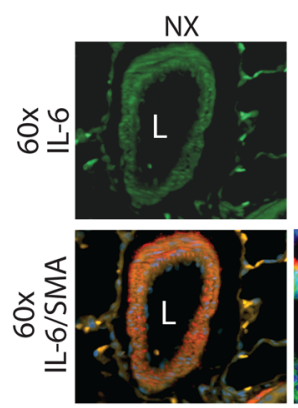

C
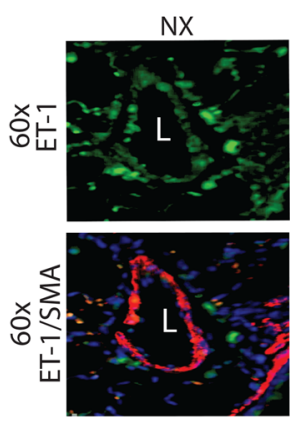

$\mathrm{HO}^{+} / \mathrm{SMA}^{+}$staining

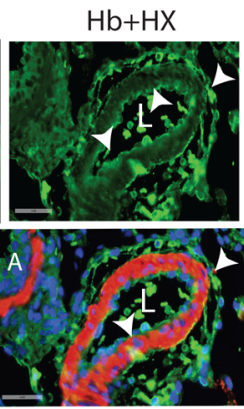

$\mathrm{IL}^{-6} \mathrm{6}^{+} / \mathrm{SMA}^{+}$staining
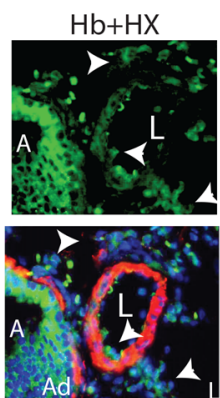

$\mathrm{ET}^{-1}{ }^{+} / \mathrm{SMA}^{+}$staining

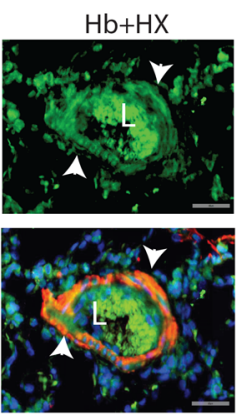

$\mathrm{Hb}+\mathrm{HX}+\mathrm{GdCl}_{3}$
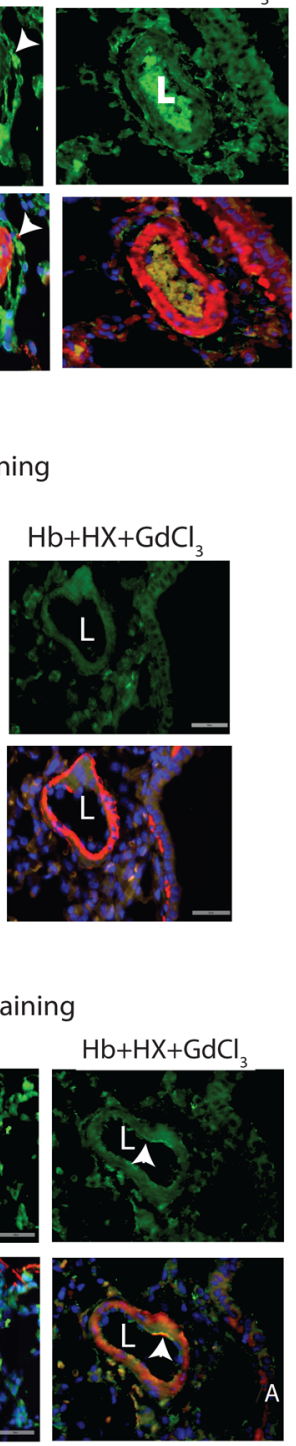

D

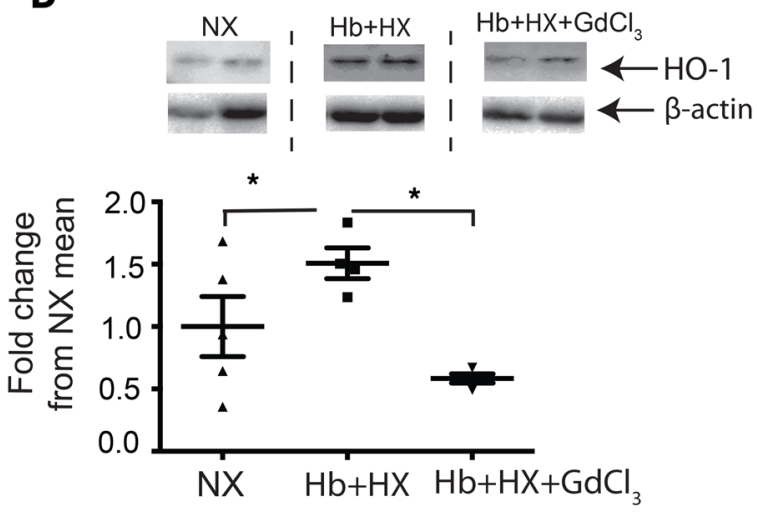

E

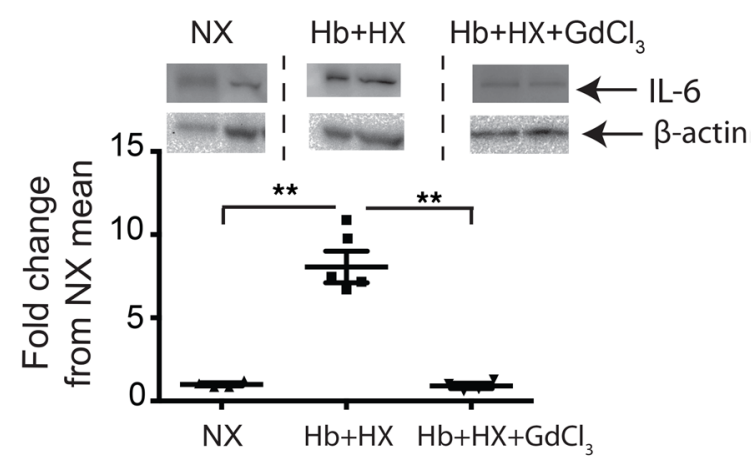

$\mathbf{F}$

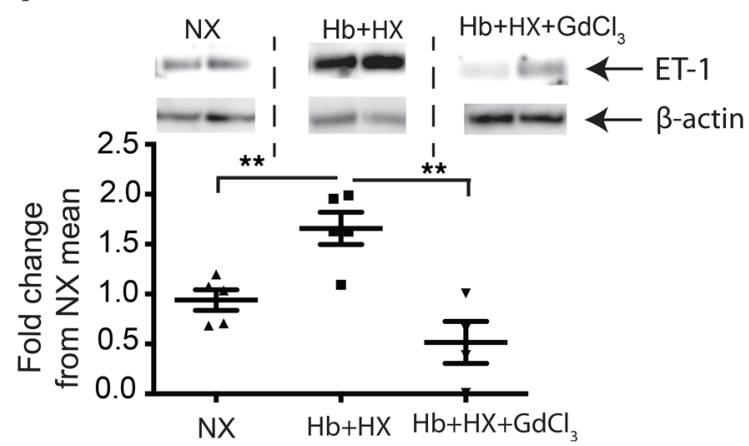

Figure 4. Pulmonary vascular microscopic examination and whole lung quantification of HO-1, IL-6, and ET-1 in rats exposed for 35 days to hemoglobin infusion and hypobaric hypoxia. (A-C) Representative microphotographs chosen from $\mathrm{NX}(n=4), \mathrm{Hb}+\mathrm{HX}(n=7)$, and $\mathrm{Hb}+\mathrm{HX}_{+} \mathrm{GdCl}$ ( $(n=7)$ groups showing only modest staining for HO-1, IL-6, and ET-1 in distal pulmonary vascular cells. (D-F) Whole lung protein quantification for HO-1, IL-6, and ET-1 demonstrate that the greatest expression of these proteins occurred in the $\mathrm{Hb}+\mathrm{HX}$ cohort and were dramatically reduced with circulating macrophage depletion with $\mathrm{GdCl}_{3}$. HO-1 and ET-1 Western blot samples were run on contiguous gels. Samples of IL-6 were completed on contiguous gels run side by side and loaded with either $\mathrm{NX}$ and $\mathrm{Hb}+\mathrm{HX}$ or $\mathrm{NX}$ and $\mathrm{Hb}+\mathrm{HX}+\mathrm{CdCl} 3$ and normalized (fold change) to $\mathrm{NX}$. Identical $\mathrm{NX}$ samples were used on both gels. Data represent mean $\pm \mathrm{SEM} ; \mathrm{NX}(n=4), \mathrm{Hb}+\mathrm{HX}(n=5), \mathrm{Hb}+\mathrm{HX}+\mathrm{CdCl}_{3}(n=4)$. Statistical analysis completed by ANOVA; ${ }^{*} P<0.05,{ }^{*} P<0.01$. White arrows show regions of positive stained cells. $L$, vessel lumen.

specifically targeted by $\mathrm{GdCl}_{3}$ administration (3 times per week) attenuated pulmonary medial and RV hypertrophy that resulted in improved echocardiography parameters (PAAT and RV wall thickness during systole/diastole), lower PAPs, improved Fulton index, and significantly reduced medial artery wall thickness. These data suggest that recruitment of circulating monocytes/macrophages is a potentially novel factor of importance in the etiology and progression of SCD-associated $\mathrm{PH}$. In addition, we noted that within 18 days of $\mathrm{Hb}+\mathrm{HX}$ exposure, circulating macrophages expressing ET-1 begin appearing in the lung and at 35 days of exposure an abundance of iron-containing macrophages expressing high HO-1, ET-1, and IL-6 accumulated in the perivascular regions of the lung. These data demonstrate a critical mechanistic role 


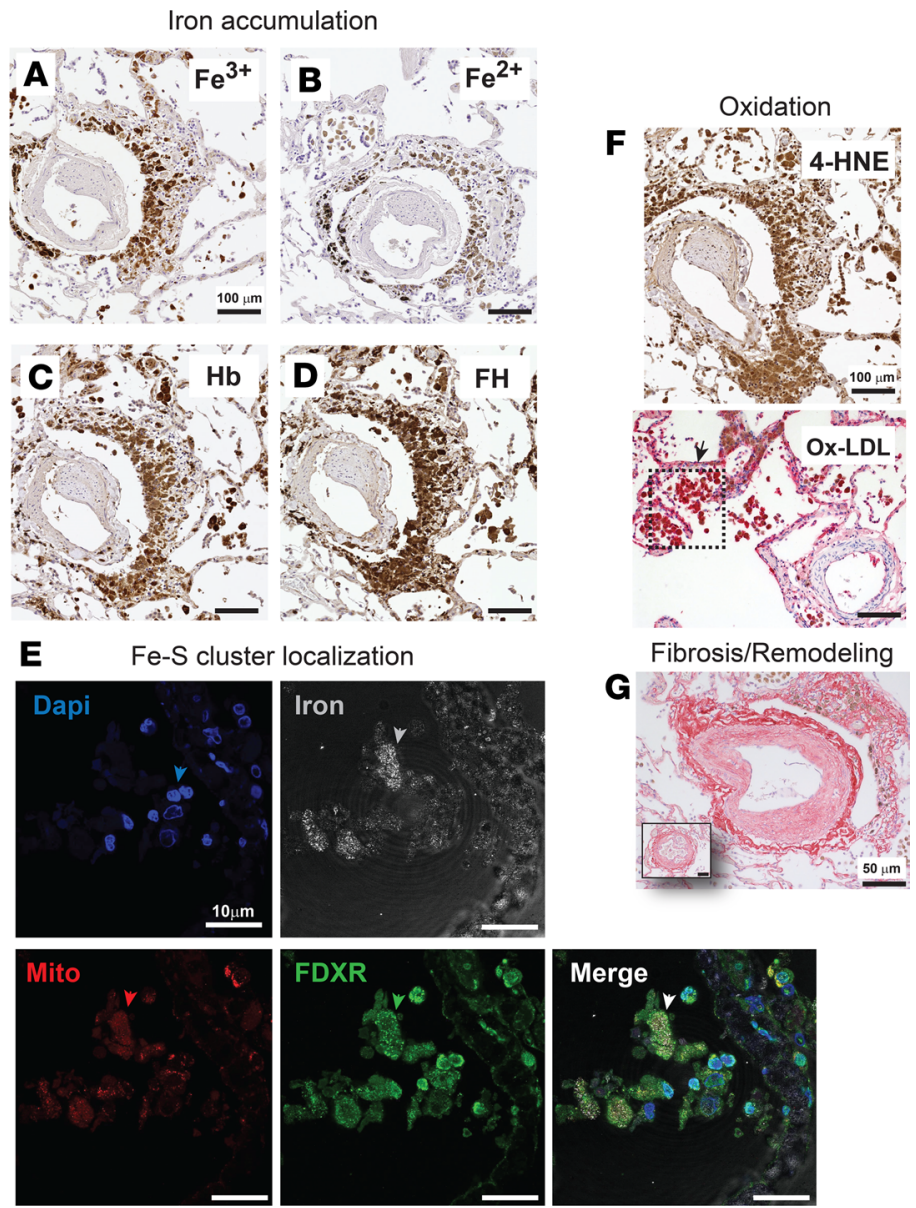

Figure 5. Characterization of iron that accumulates within SCD PHassociated macrophages and the effect on downstream targets. (A) Accumulation of iron in adventitial macrophages in the ferric $\left(\mathrm{Fe}^{3+}\right)$ oxidation state, as determined by Perls iron staining and (B) in the ferrous $\left(\mathrm{Fe}^{2+}\right)$ oxidation state. (C) Abundant accumulation of native hemoglobin $(\mathrm{Hb})$ within these tissue sites and (D) a robust expression of ferritin-heavy chain (FH). (E) Localization of iron within ferredoxin reductase. Nuclei $(\mathrm{DAPI})=$ blue, iron = gray (light reflection, $633 \mathrm{~nm}$ ), mitochondria $($ mito) $=$ red, ferredoxin reductase $(F D X R)=$ green, followed by merged images. (F) The extent of 4-hydroxynonenal immune reactivity and $0 x-L D L$ immunoreactivity in macrophages. (G) Localization and proximity of remodeled and fibrosis across vascular tissue (inset shows a plexiform lesion with extensive fibrosis). All scale bars and dimensions are listed on the initial image for each panel. Representative images were obtained from NX $(n=4)$, $\mathrm{Hb}+\mathrm{HX}(n=7), \mathrm{Hb}+\mathrm{HX}+\mathrm{CdCl}_{3}(n=7)$.

for circulating monocytes/macrophage in the development/progression of HX/hemolytic PH. Increased circulating concentrations of ET-1 are reported to occur during systemic inflammatory response syndrome and induce $\mathrm{PH}$ in that setting (29). In work by McKenna et al. (29), hepatic resident macrophages express and are the cellular source for circulating ET-1, which is hypothesized to act far from its site of production and release to cause local blood flow dysregulation and $\mathrm{PH}$. However, in our $\mathrm{Hb}+\mathrm{HX}$ rat model, the temporal evaluation of plasma ET-1 concentration at baseline, 18 days, and 35 days showed no differences among $\mathrm{NX}, \mathrm{Hb}+\mathrm{HX}$, and $\mathrm{Hb}+\mathrm{HX}+\mathrm{GdCl}_{3}$ groups (data not shown), suggesting that a localized release emanating from accumulated perivascular macrophages is likely occurring in our study.

The contribution of recruited circulating macrophages in the progression of pulmonary vascular remodeling for any type of PH remains largely unknown (14). It is generally hypothesized that under stress, lung resident macrophages instruct parenchymal and nonparenchymal cells, herein referred to as client cells, to mount an appropriate response, including the recruitment of blood monocytes (14). In the development of $\mathrm{PH}$, it is hypothesized that malfunctioning of this intricate cross-talk between resident and recruited macrophages with client cells results in permanent activation of macrophages with the subsequent progression to nonresolving inflammation as the driver to pulmonary vascular remodeling (30). Relevant to the current study, circulating macrophages appear to be responding to areas of nonheme iron accumulation as a harmful agent and are subsequently polarized toward a proinflammatory PH phenotype. It is unknown in our rat model whether 35 days of $\mathrm{Hb}$ infusion with $\mathrm{HX}$ exposure allows enough time in the progression of pulmonary vascular disease, such that these macrophages are permanently activated. However, in the context of SCD, where throughout an individuals' lifetime lung tissue is repeatedly exposed to $\mathrm{Hb}$ extravasation, HX, and the biochemical consequences, recruited monocytes/macrophages may be more likely to be permanently reprogrammed to a nonresolving phenotype that advances the progression of $\mathrm{PH}$.

HO-1 is generally considered an essential antioxidant and cytoprotective enzyme that catalyzes the degradation of heme and protects against oxidative stress and typically is coexpressed alongside IL-10 in an 

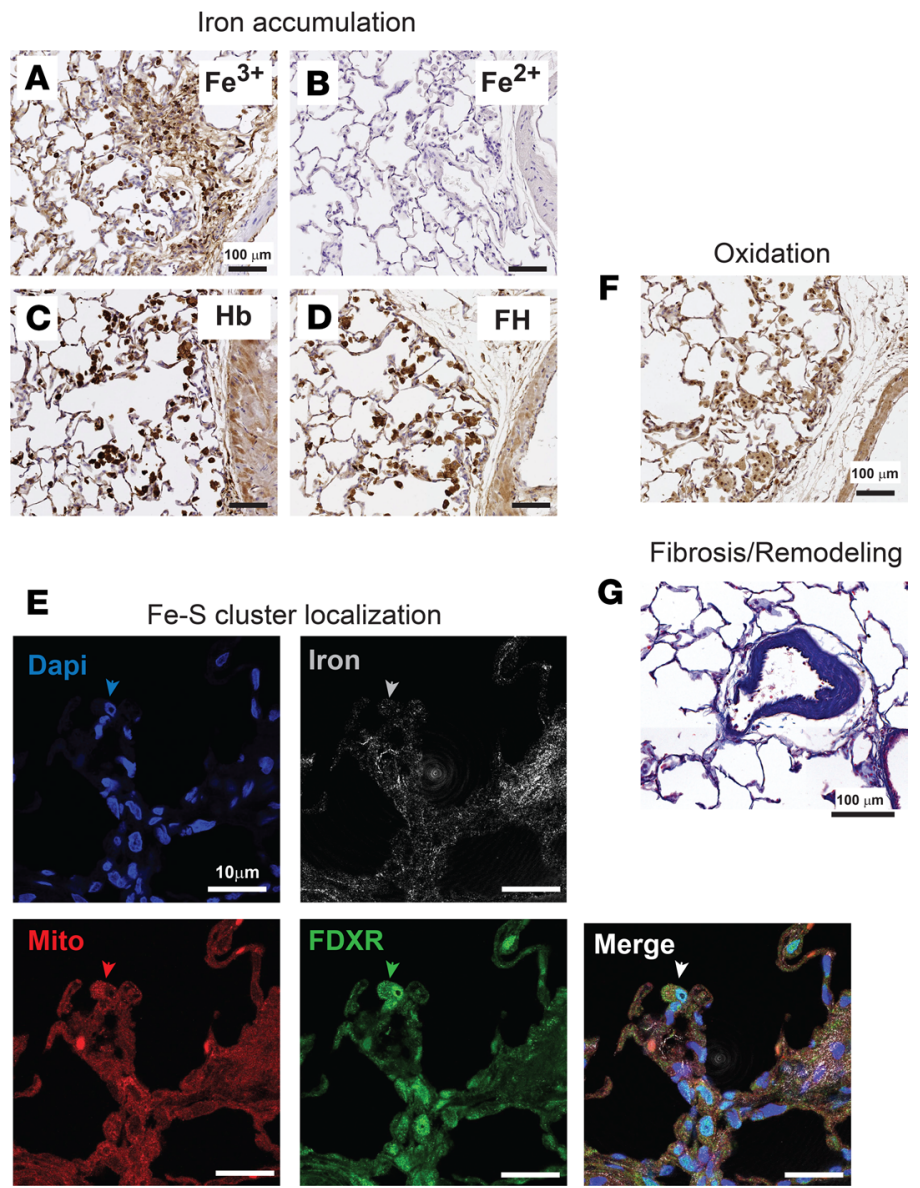

Fibrosis/Remodeling

G
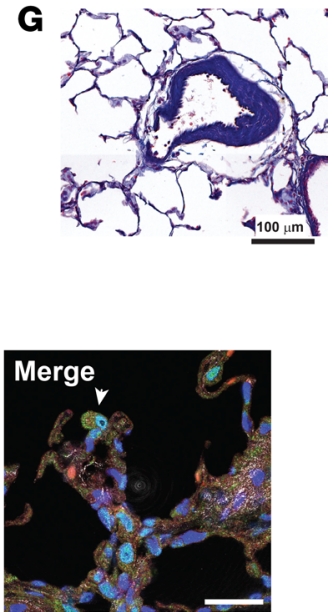

Figure 6. Characterization of iron that accumulates within rat $\mathrm{Hb}+\mathrm{Hx}$ PH-associated macrophages and the effect on downstream targets. (A) Accumulation of iron in adventitial macrophages in the ferric $\left(\mathrm{Fe}^{3+}\right)$ oxidation state, as determined by Perls iron staining and (B) in the ferrous $\left(\mathrm{Fe}^{2+}\right)$ oxidation state. (C) Abundant accumulation of native hemoglobin $(\mathrm{Hb})$ within these tissue sites and (D) a robust expression of ferritin-heavy chain (FH). (E) Localization of iron within ferredoxin reductase. Nuclei (DAPI) = blue, iron = gray (light reflection, $633 \mathrm{~nm}$ ), mitochondria (mito) = red, ferredoxin reductase $($ FDXR) $=$ green, followed by merged images. (F) The extent of 4-hydroxynonenal immune reactivity in macrophages. (C) Localization and proximity of remodeled and fibrosis across vascular tissue. All scale bars and dimensions are listed on the initial image for each panel. Representative images were obtained from NX $(n=4), \mathrm{Hb}+\mathrm{HX}(n$ $=7), \mathrm{Hb}+\mathrm{HX}+\mathrm{CdCl}_{3}(n=7)$.

antiinflammatory macrophage phenotype $(10,31)$. Thus, it was not surprising in the model that we see elevated concentrations of HO-1 in both the vasculature and recruited circulating monocytes/macrophages. Vascular HO-1 is likely responding to $\mathrm{Hb}$-mediated oxidative stress, as excess $\mathrm{Hb}$ contacts pulmonary vascular endothelial cells. In contrast, increased expression of HO-1 in macrophages is indicative of a $\mathrm{Hb}$ clearance phenotype, which is generally considered antiinflammatory (26). Thus, it is notable that we observe recruited circulating macrophages expressing high HO-1 concentrations alongside elevated expression of inflammatory, vasoactive, and mitogenic mediators. In our rat model, we believe this is likely a reflection of a circulating monocyte/macrophage participation in clearance of $\mathrm{Hb}$ within the blood compartment, likely in the earlier time frame of $\mathrm{Hb}$ exposure. Our data suggest that at later time points as lung injury occurs(possibly because of $\mathrm{Hb}$-induced iron accumulation), these same macrophages are subsequently recruited to the perivascular regions of the lung. Under these circumstances, it is reasonable to assume the increased expression of HO-1 observed in macrophages at day 35 is part of the heme degradation process that began before recruitment to the lung. Once in the lung, the recruited macrophage appears to be responding to client cells that promote progrowth/PH phenotype that upregulate IL-6 and ET-1 protein expression.

In the current study, depleting circulating monocytes/macrophages revealed that $\mathrm{Hb}+\mathrm{HX}$ mediated the increase in the inflammatory, vasoactive, and mitogenic factors (IL-6 and ET-1) at day 18. It appears that this duration of $\mathrm{Hb}+\mathrm{HX}$ does not significantly enhance pulmonary vascular remodeling above that of general chronic HX. However, at day 35 our data suggest a strong association between $\mathrm{Hb}+\mathrm{HX}$ and expression of IL-6 and ET-1 macrophages in lung perivascular regions. This appears to be associated with more severe pulmonary vascular remodeling that could be attributed to $\mathrm{Hb}$ or $\mathrm{HX}$ exposure alone. These data support the concept that cell type and location of where these factors are derived may be necessary in the development of SCD PH.

Our $\mathrm{Hb}+\mathrm{HX} \mathrm{PH}$ model used in the present study was developed and characterized by a broad application of diseases associated with $\mathrm{Hb}+\mathrm{HX}$-mediated pathology. Thus, as described elsewhere, our model cannot fully mimic the complexities of human conditions such as SCD (18). Nonetheless, our model provides 


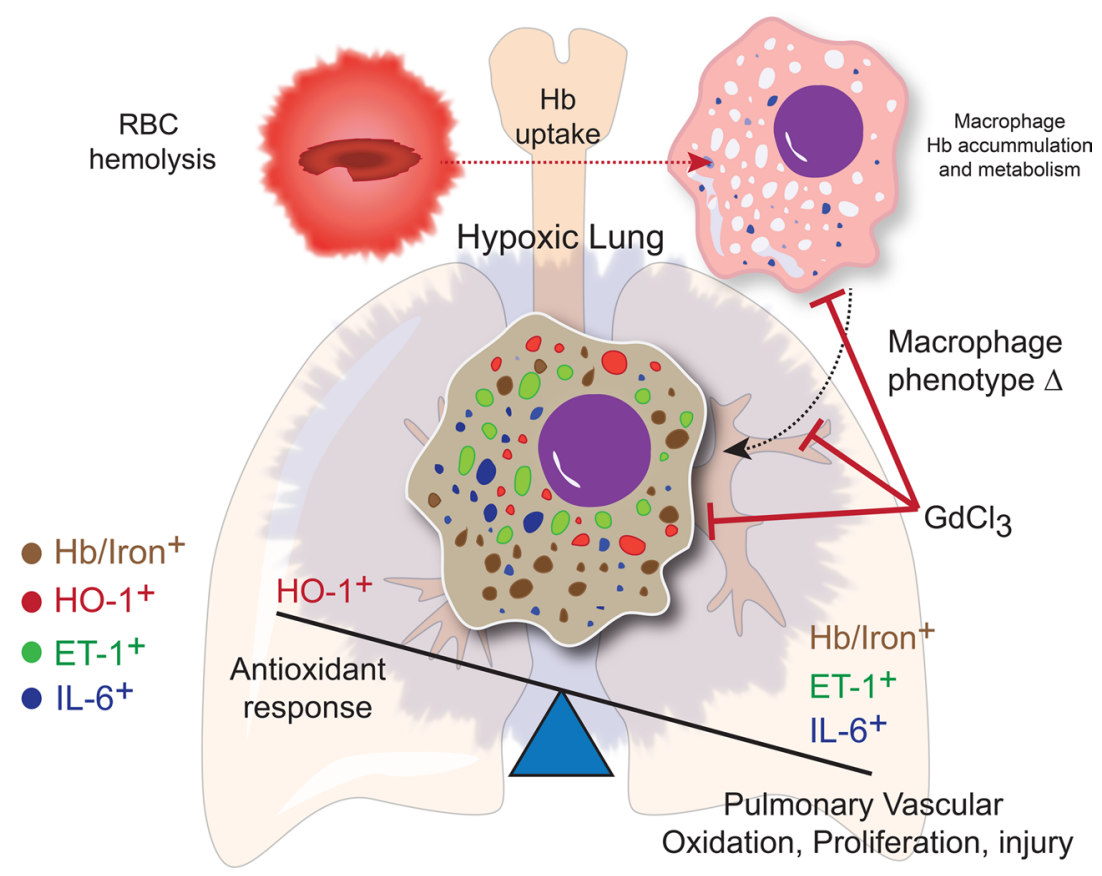

Figure 7. Schematic illustrating the pulmonary vascular response to Hb during chronic underlying hypoxia. Hemolysis of sickled red blood cells (RBCs) leads to uptake of $\mathrm{Hb}$ by macrophages. Hemoglobin is either metabolized to iron $\mathrm{Fe}^{2+} / \mathrm{Fe}^{3+}$ or accumulates in macrophages. Upregulation in $\mathrm{HO}-1$ leads to carbon monoxide and bilirubin, which function as vasodilators and antioxidants, respectively. In addition to accumulation of prooxidants ( $\mathrm{Fe}^{2+} / \mathrm{Fe}^{3+}$ and hemoglobin), the effect of hypoxia in combination with $\mathrm{Hb}$ exposure appears to lead toward ET-1 upregulation, creating a mitogenic and vasoconstrictive effect. In addition, IL- 6 is upregulated, leading to inflammation and vascular proliferation. Together, $\mathrm{Fe}^{2+} / \mathrm{Fe}^{3+}$, hemoglobin, ET-1, and IL-6 tip the balance away from the antioxidant protective effects of $\mathrm{HO}-1$ and its heme metabolizing metabolic byproducts. We suggest that this macrophage phenotype is unique to hypoxic disease where hemolysis occurs. Moreover, its accumulation in perivascular regions of the lung is an important mediator of pulmonary vascular oxidation, remodeling, and fibrosis in the progression of PH that is potentially unique to SCD.

a basis to understand the events associated with $\mathrm{Hb}$ and its contribution to the pathophysiology of disease, including how $\mathrm{Hb}$ influences the macrophage phenotype during bouts of $\mathrm{HX}$ (Figure 7).

Conclusion. The data presented here in a rat model of $\mathrm{Hb}+\mathrm{HX}$-mediated pathology that condenses a lifetime of intermittent exposure to $\mathrm{Hb}$ and $\mathrm{HX}$ confirms that free $\mathrm{Hb}$ acts as a disease-modifying agent in $\mathrm{PH}$. Depletion of circulating macrophages with $\mathrm{GdCl}_{3}$ attenuated the cumulative effects of $\mathrm{Hb}+\mathrm{HX}$ and therefore demonstrates a critical role for macrophages in pulmonary vascular disease involving $\mathrm{Hb}$ exposure and $\mathrm{HX}$. In the present study, extracellular $\mathrm{Hb}+\mathrm{HX}$ increased pulmonary vascular remodeling in a time frame associated with recruitment of circulating iron-positive macrophages expressing a potentially unique $\mathrm{HO}-1^{+}$, ET- $1^{+}$, and IL- $6^{+}$cellular phenotype to the perivascular regions. In addition, this macrophage phenotype was validated in lung tissue from 3 deceased SCD patients suffering from PH and RV failure. The present results support the concept that the macrophage is a critical mediator in the progression of SCD PH and may provide a therapeutic target in some SCD patients.

\section{Methods}

Human lung tissue. Deidentified human lung tissue was obtained from deceased SCD patients with identified PH from the University of Colorado Denver Anschutz Medical Center and the Royal London Hospital. Use of deceased lung tissue was considered by the Colorado Multiple Institution Review Board and deemed as nonhuman subject research and given an exempt status. Lung tissue from non-SCD patients not identified as having PH was obtained from US Biomax Inc.

Animals. Male Sprague-Dawley rats $(n=58)$ weighing between 300 and $350 \mathrm{~g}$, approximately 10 weeks of age, were obtained from a commercial vendor (Charles River). All animals survived the surgical procedure and indwelling catheterization into the jugular vein. None of the rats exhibited any signs or symptoms indicative of systemic infection. After surgery, wounds healed within 14 days. 
$\mathrm{Hb}+H X$ (group 5) PH model. Rats exposed to both continuous $\mathrm{Hb}$ infusion $(35 \mathrm{mg} / \mathrm{d} \mathrm{Hb}$ ) and chronic hypobaric HX (simulated high altitude; $5500 \mathrm{~m}, 18,000 \mathrm{ft}$ ) for 35 days developed a more severe $\mathrm{PH}$ then simple hypoxic exposure $(17,18)$. This group $5 \mathrm{PH}$ rodent model presents with higher pulmonary arterial pressures and pulmonary vascular resistance, greater pulmonary medial vascular wall thickening, and greater accumulation of adventitial macrophages compared with $\mathrm{HX}$-induced $\mathrm{PH}$ alone $(17,18)$.

In the current study, animals were randomly assigned to 1 of 3 groups: (a) NX $(n=8)$; (b) $\mathrm{Hb}+\mathrm{HX}$ ( $n=14)$; (c) $\mathrm{Hb}+\mathrm{HX}$ treated 3 times per week with $10 \mathrm{mg} / \mathrm{kg} \mathrm{GdCl}\left(\mathrm{Hb}+\mathrm{HX}+\mathrm{GdCl}_{3}\right)(n=14)$. The animals were divided equally in each group and euthanized at either 18 or 35 days. To verify the reproducibility of $\mathrm{Hb}$-induced effects of our model system, an additional group of animals exposed to HX (HX; $n=10)$ were also studied at 18 and 35 days. Unless otherwise stated, HX-only rats are not included in the primary comparisons.

$\mathrm{GdCl}_{3}$ (catalog G7532; MilliporeSigma) $10 \mathrm{mg} / \mathrm{mL}$ was dissolved in sterile $0.9 \% \mathrm{NaCl}$, and a $1-\mathrm{mL}$ dose was delivered via the tail vein. An 18-day pilot study using 6 rats randomly divided into 2 groups, untreated $(n=3)$ or treated with $\mathrm{GdCl}_{3}(n=3)$, was completed to confirm macrophage depletion for this dose and schedule. As expected, qRTPCR analysis for $\mathrm{CD} 163^{+}$and $\mathrm{CD} 68^{+}$cells in the liver demonstrated macrophage depletion (data not shown).

The following Abcam antibodies were used for Western blot analysis: mouse anti- $\beta$ actin 1:1000 (cata$\log$ ab8226); mouse anti-IL-6, 1:1000 (catalog ab9324); rabbit anti-endothelin 1, 1:500 (catalog ab117757); mouse anti-heme oxygenase 1, 1:2500 or $4 \mu \mathrm{g} / \mathrm{mL}$ (catalog ab13248); mouse anti-CD68, 1:500 (catalog ab955); a biotinylated secondary goat anti-mouse or goat anti-rabbit, 1:1000 to 1:10,000 (Vector Labs).

Immunofluorescence and immunohistochemistry analysis was completed using the following antibodies: mouse/rabbit anti-SMA 1:100 (catalog ab5694 and ab7817); rabbit anti-heme oxygenase 1:250 (HO1; catalog ab13248); mouse anti-IL- 6, 1:1000 (catalog ab9324); rabbit anti-endothelin1, 1:500 (catalog ab117757); mouse anti-CD163, 1:20 (Santa Cruz, catalog sc8-58965); secondary antibody used were either Alexa Fluor 488, 1:500, or Alexa Fluor 555, 1:500 (Invitrogen). Vectashield mounting medium with DAPI was used to mount slides (catalog H-1200). Rabbit anti-Hb- $\alpha$-chain, 1:200 (Abcam, catalog ab2492); rabbit anti-Ferritin-Heavy chain, 1:500 (Abcam, catalog ab65080); rabbit anti-oxidized LDL, 1:500 (Abcam, catalog ab14519); and rabbit anti-4-Hydroxynonenal (4-HNE), 1:500 (Alpha Diagnostics, catalog HNE11-S) were used. Peroxidase substrate kit DAB (catalog SK-4100, Vector Labs) was used to preform Perls/Turnbull iron staining on lung, kidney, and spleen tissue sections.

iPRECIO infusion pump placement. Programmable infusion pumps (iPRECIO) were placed subcutaneously as previously described $(17,18)$. iPRECIO pumps were programmed to deliver $\mathrm{Hb}(35 \mathrm{mg} / \mathrm{d}$ or 250 $\mu \mathrm{g} / \mu \mathrm{L})$ or saline at an infusion rate of $6 \mu \mathrm{L}$ per hour for either 18 or 35 days. Pumps were refilled using a sterile 3-mL syringe and 25-G needle with fresh aliquots of $\mathrm{Hb}$ or saline every 3-4 days. At a dose of 35 $\mathrm{mg} / \mathrm{d}$, we have previously shown that total plasma heme concentrations were in the range of values similar to a mild to moderate chronic hemolytic state (17).

Endotoxin and catalase-free human adult $\mathrm{Hb}\left(\mathrm{HbA} ;\left[\mathrm{Fe}^{2+}\right]\right)$. Purified human endotoxin-free $\mathrm{Hb}$ (LPS $<0.5$ endotoxin units [EU]) was prepared from outdated blood as previously described (32). In brief, an additional chromatography step was included to remove catalase. Approximately $1 \mathrm{~g} \mathrm{Hb}$ protein was loaded onto a GE Healthcare glass column (HR 16/50: 11/2 inches $\times 26$ inches) packed with Superose (code 17-0489-01, Amersham Biosciences) and run at $4^{\circ} \mathrm{C}$ and a flow rate of $2 \mathrm{~mL} / \mathrm{h}$. Hb protein was collected and was followed by buffer switching to $0.1 \mathrm{NaCl}$ to remove catalase from the column. Several runs were pooled and concentrated to $200 \mathrm{mg} / \mathrm{mL}$ using Centricon Plus - 70 with $30-\mathrm{kDa}$ cutoff membrane filters (Millipore). The starting composition of $\mathrm{Hb}$ was $96.5 \% \pm 1.3 \% \mathrm{Fe}^{2+}, 3.50 \% \pm 0.23 \% \mathrm{Fe}^{3+}$, and no measurable hemichrome. Endotoxin concentration was less than $0.5 \mathrm{EU} / \mathrm{mL}$, as determined by the Limulus amebocyte lysate (LAL) assay, and failed to activate macrophages in culture.

Echocardiography. Echocardiographic analysis was performed at 2-week intervals using a high-resolution in vivo microimaging Vevo770 system (Visual-Sonics). Care was taken to follow the guidelines for measuring cardiac physiology in rats established by the American Physiological Society (33). For each analysis, rats were anesthetized via an isoflurane $/ \mathrm{O}_{2}$ mixture with induction at $4 \%$ and maintenance between $1.5 \%$ and $3 \%$, and body temperature was maintained at $37^{\circ} \mathrm{C}$ via a heated surgical pad. As described by Cavasin et al. (34), pulse-wave Doppler imaging of the pulmonary outflow was recorded in the parasternal short-axis view at the level of the aortic valve. Animals were then monitored during the recovery from anesthesia; upon full recovery, they were returned to their respective housing. 
Endpoint blood pressure measurements. Pulmonary blood pressures were measured with a $1.9 \mathrm{~F}$ pressure-volume catheter placed in the main PA in an open-chest procedure. Correct placement of the catheter was confirmed by observing the normal rise in diastolic pressure as the catheter was moved into the PA. Systemic blood pressure was monitored with a catheter inserted in the femoral artery. Cardiac performance was assessed using an ADV500 pressure-volume system (Transonic/Scisense), and data acquired and analyzed with Labscribe2 (iWorx). For all measurements, animals were anesthetized with $5 \%$ and maintained at $2 \%$ isoflurane, and body temperature was maintained at $37^{\circ} \mathrm{C}$.

Blood and organ collection. After blood pressure measurements, animals were deeply anesthetized (5\% isoflurane) and then exsanguinated via RV or inferior vena cava direct stick; blood was placed in a vacutainer with EDTA and centrifuged. The plasma was collected, snap frozen in liquid nitrogen, and stored at $-80^{\circ} \mathrm{C}$ until analysis. The femoral artery was severed, and the vasculature was perfused with PBS $(120 \mathrm{~mL})$ via the RV to remove blood in the lungs, kidneys, spleen, and liver. The kidneys, spleen, and liver were cut in 2 sections, one piece was placed in 10\% formalin and the other in AllProtect (Qiagen). The right lung lobes were tied off at the right main bronchus, removed, and a piece was placed in AllProtect, and another piece was snap frozen. The left lung was fixed with $10 \%$ formalin $(3 \mathrm{~mL})$ by airway inflation under constant pressure at $25 \mathrm{~cm} \mathrm{H}_{2} \mathrm{O}$ pressure, and the entire lung-heart bloc was removed. The hearts were separated from the lungs and the atria were dissected from the ventricles. The RV was carefully cut away from the left ventricles plus septum $(\mathrm{LV}+\mathrm{S})$ and weighed for assessment of the Fulton index (RV hypertrophy; RV/LV $+\mathrm{S}$ ). After 24 hours, the formalin-fixed organs were removed from $10 \%$ formalin and placed in $70 \%$ ethanol and prepared following standard methods for morphometric and immunohistochemical analyses.

qtPCR for $C D 163^{+}$liver cells. RNA was isolated from whole lung or liver tissue using Qiagen RNeasy Plus Mini Kit with gDNA filter column (Qiagen). RNA was quantified spectrophotometrically (NanoDrop 1000), and equal amounts (1 microgram) were loaded with Quanta cDNA Supermix (Quanta Biosciences) for cDNA synthesis. cDNA was diluted 1:10 in TE buffer for downstream reactions. Primers for rat $\beta$-actin (Qiagen QuantiTect QT00193473) and rat CD163 (Qiagen QuantiTect QT00449113) were used in reactions with $100 \mu \mathrm{g}$ cDNA and Quanta PerfectCT a SYBR Green Master Mix. Ninety-six-well PCR plates were run on an Applied Biosystems AB7300 (Thermo Fisher), with initial denaturing $\left(95^{\circ} \mathrm{C}, 2\right.$ minutes) followed by 40 cycles of denaturing $\left(95^{\circ} \mathrm{C}, 15\right.$ seconds), annealing $\left(55^{\circ} \mathrm{C}, 30\right.$ seconds), and extension $\left(72^{\circ} \mathrm{C}\right.$, 30 seconds). A melting curve was run to confirm the specificity of PCR products. Experimental and reference genes were run on the same plates and relative quantification determined by the $\Delta \mathrm{C}_{\mathrm{T}}$ method.

Western blot analysis. Protein was isolated from the whole lung and placed in NP40 lysis buffer with proteinase $\mathrm{K}$ inhibitors. The tissue was homogenized using a TissueMiser (Thermo Fisher), and concentrations were determined using a Pierce BCA Protein Assay. Briefly, the analysis was performed on a minimum of $n=4$ animals per cohort using $30 \mu \mathrm{g}$ of sample protein run under denaturing and reducing conditions on Bio-Rad Criterion Tris-HCl 12.5\% gels (Bio-Rad, catalog 3450016) with a Bio-Rad SDS-Page blot system. All proteins were normalized to $\beta$-actin, which was probed on the same membrane as the target protein and expressed as fold over NX control. In instances where fold over NX control was compared between gels, the same NX control samples were used on both gels acting as a standard and gels were run side by side. Gels were imaged on an Alpha Innotech gel documentation system (Protein Simple) and densitometric analyses were performed using ImageJ software (version 1.44o, NIH).

Immunohistochemistry. Formalin-fixed, paraffin-embedded lung, spleen, and liver tissue was sectioned by the University of Colorado Histology Core. Five-micron lung sections were stained with (a) H\&E by standard procedures to assess the accumulation of perivascular cells as well as vessel wall thickness; (b) Van Geisen staining for Elastin fibers by immersing slides in Verhoeff's hematoxylin for 30 minutes, differentiated in $2 \%$ ferric chloride, washed with deionized water and counterstained with Van Gieson's stain for 5 minutes, dehydrated, and coverslipped; (c) SMA using a biotinylated horse anti-mouse immunoglobulin followed by a 3,3'-diaminobenzidine (DAB) for development to quantify small arterial muscularization; (d) Masson's trichrome staining (collagen) in which rat tissue was refixed in Bouin's solution, washed in deionized water, stained in Weigert's iron hematoxylin, Biebrich scarlet-acid fuchsin solution, and finally phosphomolybdic-phosphotungstic acid differentiation; and (e) Picrosirius Red (collagen) in which human tissue was refixed with Picrosirius Red Solution for 10 minutes and then washed in acidified water $(5 \mathrm{~mL}$ glacial acetic acid in $1 \mathrm{~L}$ deionized water), dehydrated in $100 \%$ ethanol, and coverslipped.

Tissue iron staining. For iron (ferrous $\left.\left[\mathrm{Fe}^{2+}\right]\right) /\left(\right.$ ferric $\left.\left[\mathrm{Fe}^{3+}\right]\right)$, sections were incubated with iron-staining reagent containing $5 \%$ potassium ferrocyanide for Perls staining (ferric $\left[\mathrm{Fe}^{3+}\right.$ iron]) or $5 \%$ potassium ferricy- 
anide for Turnbull staining (ferrous $\left[\mathrm{Fe}^{2+}\right.$ iron]) and $2 \%$ hydrochloric acid, incubated with $0.3 \%$ hydrogen peroxide and 0.01 $\mathrm{M}$ sodium azide in methanol, and then rinsed in $0.1 \mathrm{M}$ phosphate buffer, $\mathrm{pH} 7.4$, incubated with diaminobenzidine (SigmaFast DAB, MilliporeSigma), washed in deionized water, and lightly counterstained with Gill's II hematoxylin.

Confocal imaging: immunofluorescence for iron sulfur cluster intracellular location. To localize intracellular iron-sulfur clusters, 5-micron lung sections were stained following conventional immunofluorescence protocol. Primary antibodies were Abcam rabbit anti-ferredoxin reductase (ab 122900, lot GR82088-4) and Abcam mouse anti-COX IV (mitochondrial marker, ab 33985, lot GR3232580-2) both diluted to 1:500; secondary antibodies were Alexa Fluor 488 goat anti- rabbit IgG (Life Technologies A11008, lot 1735088) and Alexa Fluor 555 goat anti-mouse IgG (Life Technologies A21422, lot 1729804) both at 1:500 dilution. Imaging done in the University of Colorado Light Microscopy core using the Olympus FV1000 FCS/RIS microscope. A 2-phase confocal imaging protocol was used; phase 1 was set to traditional wavelengths for DAPI, FITC, and TRITC; and phase 2 was set for iron reflection at $633 \mathrm{~nm}$.

Vessel wall thickness. The entire tissue field on each H\&E-stained slide was scanned using a Leica AperioCS2 microscope. Analyses of the scanned images were performed using the Aperio eSlide manager software (Leica). Proximal vessels (outside diameter of 50-250 microns) were analyzed for medial wall thickness at 4 points around the vessel circumference and lumen diameter along 2 axes. Wall thickness was expressed as the ratio of medial wall width to lumen radius.

Nonheme iron visualization in the lung was detected using Perls staining method with DAB intensification as previously described (35).

Statistics. For all groups, the mean \pm SEM is reported. Statistical comparisons for data measurements were completed with either 1-way ANOVA (36) for $\mathrm{NX}, \mathrm{Hb}+\mathrm{HX}$, and $\mathrm{Hb}+\mathrm{HX}+\mathrm{GdCl}_{3}$ treatment (protein analysis) or 2-way ANOVA for analysis between time (morphology and hemodynamic analysis). Echocardiography data were also analyzed by a univariate repeated-measures test using JMP (SAS Cary). All post hoc analyses were completed with unpaired, 2-sided 2-tailed Student's $t$ test with a Bonferroni correction unless otherwise noted. Statistical analyses were performed using GraphPad Prism with statistical significance set at $P \leq 0.05$.

Study approval. This study was carried out in strict accordance with recommendations in the Guide for the Care and Use of Laboratory Animals (National Academies Press, 2011). All experimental protocols were reviewed and approved by the Institutional Animal Care and Use Committee at the University of Colorado Denver Anschutz Medical Campus (protocol 00297).

\section{Author contributions}

RN, KH, ENG, KRS, PWB, and DCI designed research studies. KR, JHB, AY, HKS, JWH, DS, AFP, PWB, and DCI conducted experiments. KR, JB, AY, HKS, RM, VK, JWH, DS, DP, PWB, and DCI acquired data. MAF, ENG, KRS, PWB, and DCI analyzed data. DP, PWB, and DCI prepared figures. MAF, VK, SKF, RN, KH, ENG, KRS, PWB, and DCI wrote the manuscript.

\section{Acknowledgments}

The present study was supported by National Heart, Lung, and Blood Institute grants 1R01HL125642-01 (to DCI), 1R01HL086680-07 (to ENG), 5P01HL014985-38 (to KRS), and T32-HL007171 (to KRS) and the Colorado Sickle Cell Treatment and Research Center (to KH and RN). The findings and conclusions in this article have not been formally disseminated by the Food and Drug Administration and should not be construed to represent any Agency determination or policy.

Address correspondence to: David Irwin, University of Colorado Anschutz Medical Campus, Research Building 2, B133, Room 8121, Aurora, Colorado 80045, USA. Phone: 303.724.3684; Email: david.irwin@ ucdenver.edu.

1. Haw A, Palevsky HI. Pulmonary hypertension in chronic hemolytic anemias: Pathophysiology and treatment. Respir Med 2018;137:191-200.

2. Simonneau G, et al. Updated clinical classification of pulmonary hypertension. J Am Coll Cardiol. 2013;62(25 suppl):D34-D41.

3. Mehari A, Klings ES. Chronic pulmonary complications of sickle cell disease. Chest. 2016;149(5):1313-1324.

4. Gladwin MT. Cardiovascular complications and risk of death in sickle-cell disease. Lancet. 2016;387(10037):2565-2574

5. Kato G, Taylor JG 6th. Pleiotropic effects of intravascular haemolysis on vascular homeostasis. Br J Haematol. 2010;148(5):690-701.

6. Rother RP, Bell L, Hillmen P, Gladwin MT. The clinical sequelae of intravascular hemolysis and extracellular plasma hemoglo- 
bin: a novel mechanism of human disease. JAMA. 2005;293(13):1653-1662.

7. Belcher JD, et al. Haptoglobin and hemopexin inhibit vaso-occlusion and inflammation in murine sickle cell disease: role of heme oxygenase-1 induction. PLoS One. 2018;13(4):e0196455.

8. Vijayan V, Wagener FADTG, Immenschuh S. The macrophage heme-heme oxygenase-1 system and its role in inflammation. Biochem Pharmacol. 2018;153:159-167.

9. Patel H, Zaghloul N, Lin K, Liu SF, Miller EJ, Ahmed M. Hypoxia-induced activation of specific members of the NF-kB family and its relevance to pulmonary vascular remodeling. Int J Biochem Cell Biol. 2017;92:141-147.

10. Rabinovitch M, Guignabert C, Humbert M, Nicolls MR. Inflammation and immunity in the pathogenesis of pulmonary arterial hypertension. Circ Res. 2014;115(1):165-175.

11. Kato GJ, Steinberg MH, Gladwin MT. Intravascular hemolysis and the pathophysiology of sickle cell disease. J Clin Invest. 2017;127(3):750-760.

12. Stenmark KR, Tuder RM, El Kasmi KC. Metabolic reprogramming and inflammation act in concert to control vascular remodeling in hypoxic pulmonary hypertension. J Appl Physiol. 2015;119(10):1164-1172.

13. Pugliese SC, et al. A time- and compartment-specific activation of lung macrophages in hypoxic pulmonary hypertension. $J$ Immunol. 2017;198(12):4802-4812.

14. Pugliese SC, Poth JM, Fini MA, Olschewski A, E1 Kasmi KC, Stenmark KR. The role of inflammation in hypoxic pulmonary hypertension: from cellular mechanisms to clinical phenotypes. Am J Physiol Lung Cell Mol Physiol. 2015;308(3):L229-L252.

15. Frid MG, et al. Hypoxia-induced pulmonary vascular remodeling requires recruitment of circulating mesenchymal precursors of a monocyte/macrophage lineage. Am J Pathol. 2006;168(2):659-669.

16. Xue J, et al. Transcriptome-based network analysis reveals a spectrum model of human macrophage activation. Immunity. 2014;40(2):274-288.

17. Buehler PW, et al. Free hemoglobin induction of pulmonary vascular disease: evidence for an inflammatory mechanism. Am $J$ Physiol Lung Cell Mol Physiol. 2012;303(4):L312-L326.

18. Irwin DC, et al. Hemoglobin-induced lung vascular oxidation, inflammation, and remodeling contribute to the progression of hypoxic pulmonary hypertension and is attenuated in rats with repeated-dose haptoglobin administration. Free Radic Biol Med. 2015;82:50-62.

19. Svendsen P, et al. Antibody-directed glucocorticoid targeting to CD163 in M2-type macrophages attenuates fructose-induced liver inflammatory changes. Mol Ther Methods Clin Dev. 2017;4:50-61.

20. Yalamanoglu A, et al. Depletion of haptoglobin and hemopexin promote hemoglobin-mediated lipoprotein oxidation in sickle cell disease. Am J Physiol Lung Cell Mol Physiol. 2018;315(5):L765-L774.

21. Howard LS, et al. Supplementation of iron in pulmonary hypertension: rationale and design of a phase II clinical trial in idiopathic pulmonary arterial hypertension. Pulm Circ. 2013;3(1):100-107.

22. Smith TG, et al. The increase in pulmonary arterial pressure caused by hypoxia depends on iron status. J Physiol (Lond). 2008;586(24):5999-6005.

23. White $\mathrm{K}$, et al. Genetic and hypoxic alterations of the microRNA-210-ISCU1/2 axis promote iron-sulfur deficiency and pulmonary hypertension. EMBO Mol Med. 2015;7(6):695-713.

24. Yu Q, et al. BOLA (BolA Family Member 3) deficiency controls endothelial metabolism and glycine homeostasis in pulmonary hypertension. Circulation. 2019;139(19):2238-2255.

25. Boyle JJ, et al. Activating transcription factor 1 directs Mhem atheroprotective macrophages through coordinated iron handling and foam cell protection. Circ Res. 2012;110(1):20-33.

26. Kaempfer T, et al. Extracellular hemoglobin polarizes the macrophage proteome toward Hb-clearance, enhanced antioxidant capacity and suppressed HLA class 2 expression. J Proteome Res. 2011;10(5):2397-2408.

27. Vallelian F, et al. Glucocorticoid treatment skews human monocyte differentiation into a hemoglobin-clearance phenotype with enhanced heme-iron recycling and antioxidant capacity. Blood. 2010;116(24):5347-5356.

28. Rafikova O, et al. Hemolysis-induced lung vascular leakage contributes to the development of pulmonary hypertension. Am $J$ Respir Cell Mol Biol. 2018;59(3):334-345.

29. McKenna S, et al. Endotoxemia Induces IкB $\beta / \mathrm{NF}-\kappa \mathrm{B}-$ dependent endothelin-1 expression in hepatic macrophages. $J$ Immunol. 2015;195(8):3866-3879.

30. Epelman S, Lavine KJ, Randolph GJ. Origin and functions of tissue macrophages. Immunity. 2014;41(1):21-35.

31. Vergadi E, et al. Early macrophage recruitment and alternative activation are critical for the later development of hypoxia-induced pulmonary hypertension. Circulation. 2011;123(18):1986-1995.

32. Elmer J, Harris DR, Sun G, Palmer AF. Purification of hemoglobin by tangential flow filtration with diafiltration. Biotechnol Prog. 2009;25(5):1402-1410.

33. Lindsey ML, Kassiri Z, Virag JAI, de Castro Brás LE, Scherrer-Crosbie M. Guidelines for measuring cardiac physiology in mice. Am J Physiol Heart Circ Physiol. 2018;314(4):H733-H752.

34. Cavasin MA, et al. Selective class I histone deacetylase inhibition suppresses hypoxia-induced cardiopulmonary remodeling through an antiproliferative mechanism. Circ Res. 2012;110(5):739-748.

35. Gelderman MP, et al. Reversal of hemochromatosis by apotransferrin in non-transfused and transfused Hbbth $3 /+($ heterozygous B1/B2 globin gene deletion) mice. Haematologica. 2015;100(5):611-622.

36. Kwon MS, et al. Methemoglobin is an endogenous toll-like receptor 4 ligand-relevance to subarachnoid hemorrhage. Int J Mol Sci. 2015;16(3):5028-5046. 